\title{
NEPHROLOGY NURSING: EARLY INTERVENTION in CHRONIC KIDNEY DISEASE
}

\author{
by
}

Kay McLaughlin

A research project submitted to the Victoria University of Wellington

in partial fulfilment of the

requirements for the degree of

Master of Arts (Applied)

in Nursing

Victoria University of Wellington 


\section{ABSTRACT}

The early diagnosis of a patient with chronic kidney failure presents enormous opportunities for the nephrology health care team. Current research has identified that appropriate and timely education and management during the early stages of kidney disease reduces health care risk to the patient and lowers associated cost.

This study explored the potential for extending the contribution nurses make in managing patients with chronic kidney disease as they progress to end stage kidney failure. In the context of a shortage of nephrologists and an escalating patient population suffering from kidney disease, the potential to include advanced nephrology nursing in early disease management was postulated. The literature was reviewed with regard to initiatives to reduce the progression of kidney failure and the prevention of associated complications. Local and international literature on advanced nursing practice and the nurse practitioner role was examined in relation to the management of chronic kidney disease.

The introduction of the nurse practitioner in New Zealand could provide an ideal framework for independent nephrology nursing. Well-established nursing practice in dialysis, transplantation and pre-dialysis provide distinct scopes of practice in these areas for independent nursing in the future. It seems likely that these sub-specialties in nephrology nursing will be the first to experience the value of the nurse practitioner.

The creation of early interventionalist nurse practitioners in nephrology health care would allow nurses to step outside these well-established sub-specialties, and provide new resources to help manage chronic kidney disease. A model of care was proposed that outlines how a nephrology nurse practitioner could work collaboratively with community health providers and the local nephrology health care team to manage the early stages of kidney disease.

It is evident that early intervention and ongoing management of patients with chronic kidney disease is currently suboptimal. The development of the nephrology nurse practitioner is an innovative way to reach the nephrology community and meet health needs in a cost-effective manner. 


\section{ACKNOWLEDGEMENTS}

I would like to thank my supervisor Cheryle Moss for her ongoing support, advice and encouragement throughout this project. I was privileged to have Cheryle guide me through this paper and give me the confidence to believe in my ideas. I appreciate her dedication and passion to enhance nursing through a commitment to knowledge and innovation.

To my husband, Murray, and children, Hannah and Elliot, thank you for your support, patience and tolerance. You have kept me going along my academic journey over the years and encouraged me to move forward in my nursing career.

Many thanks to Dr Nick Polaschek, who gave his time to allow me to discuss and clarify my ideas with him. His wealth of knowledge, experience and ongoing encouragement has been invaluable.

Thank you to my colleagues in the Renal Department at Capital and Coast District Health, especially Miranda Walker, for their support and assistance. 


\section{TABLE OF CONTENTS}

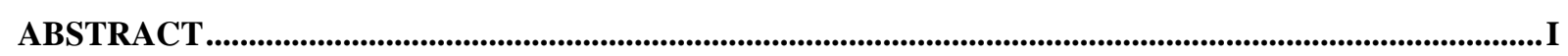

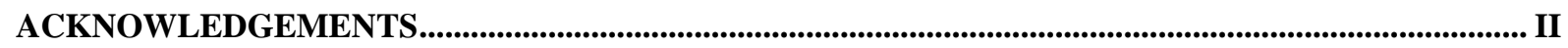

TABLE OF CONTENTS.......................................................................................................................

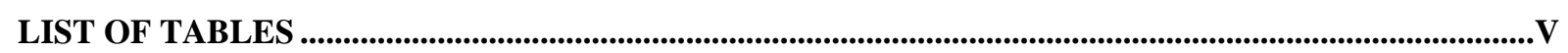

LIST OF FIGURES ............................................................................................................................................

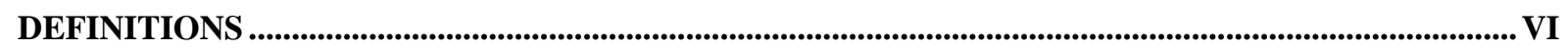

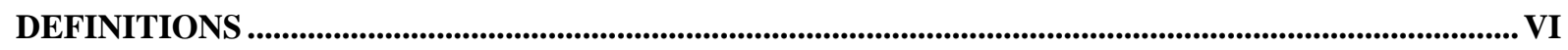

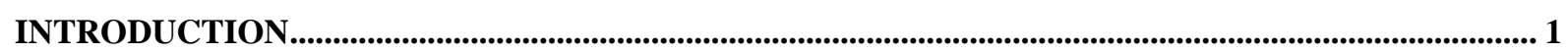

SECTION ONE: KIDNEY DISEASE AND ITS IMPACT ON NEW ZEALANDERS ................................. 4

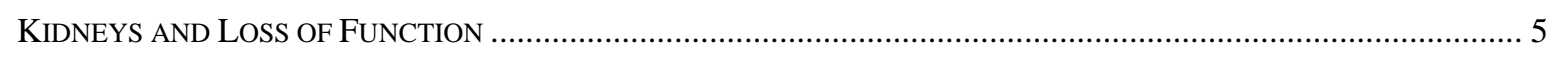

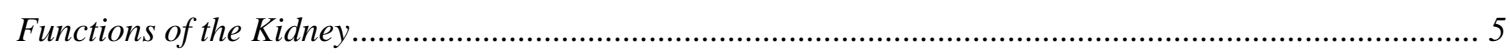

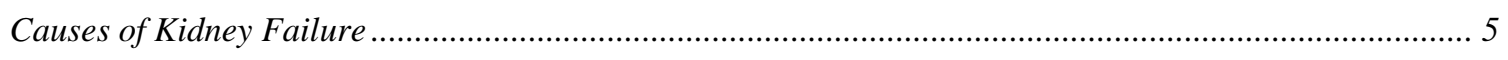

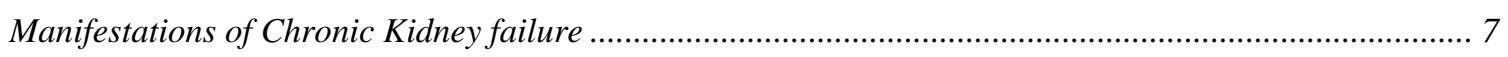

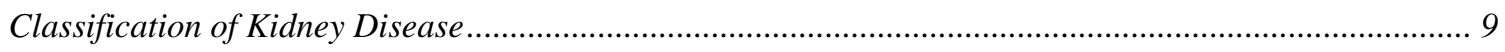

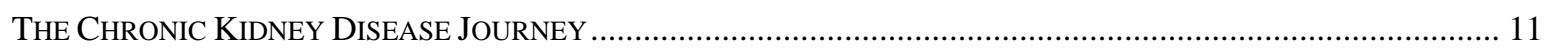

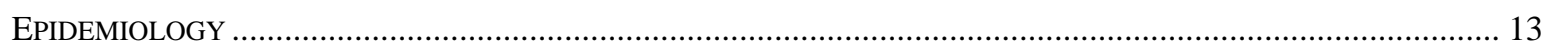

SECTION TWO: MANAGEMENT OF CHRONIC KIDNEY DISEASE ....................................................... 17

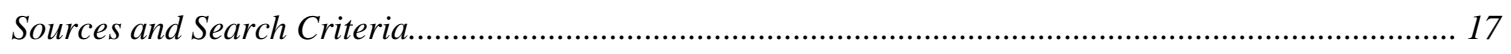

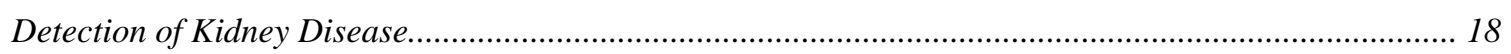

Best Practice in the Management of EARly Chronic Kidney Disease ................................................ 19

Chronic Kidney Disease: Specific Management Strategies..................................................................... 20

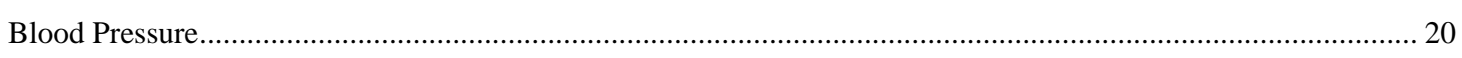

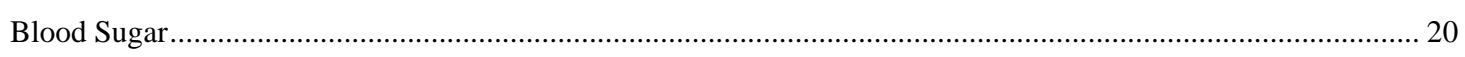

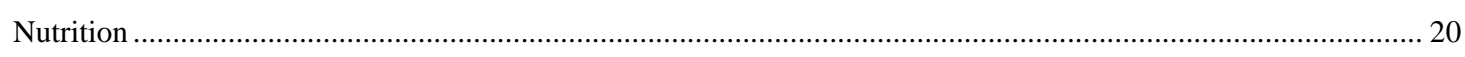

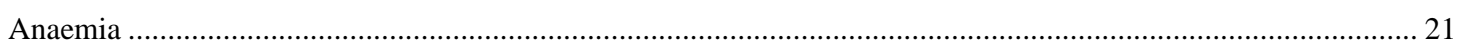

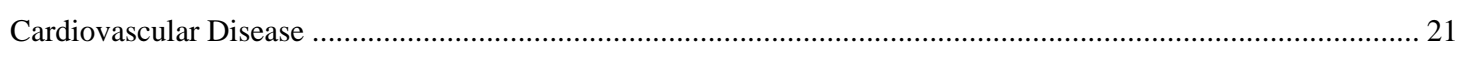

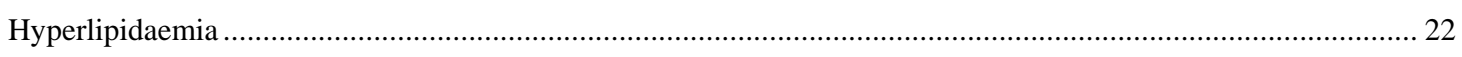

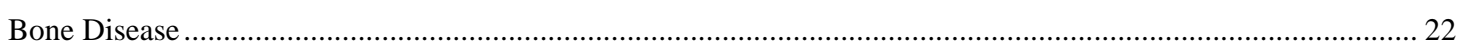

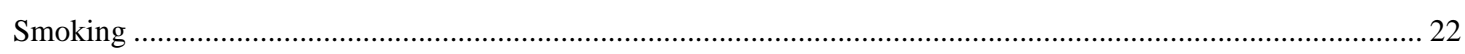

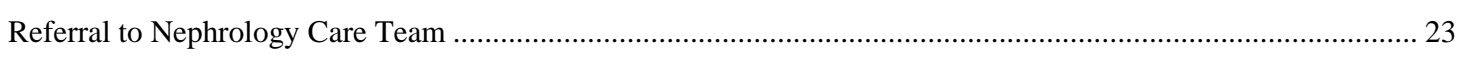

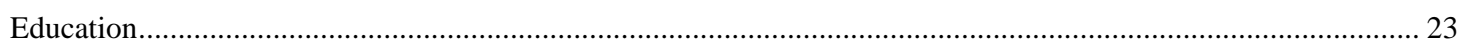

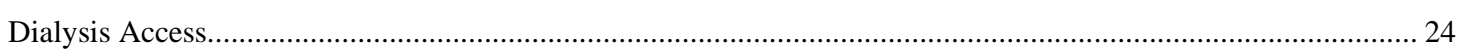




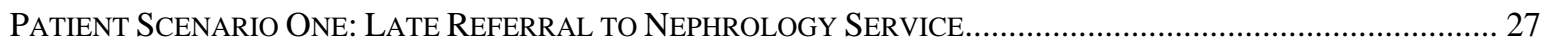

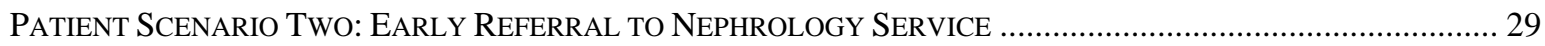

SECTION FOUR: NURSING PRACTICE AND AN EARLY INTERVENTION SERVICE ................... 31

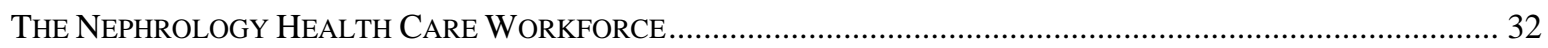

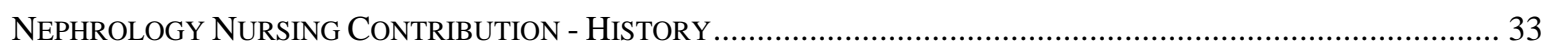

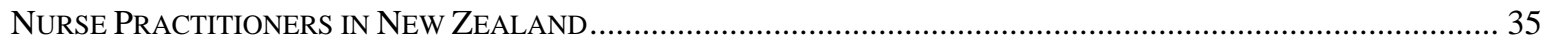

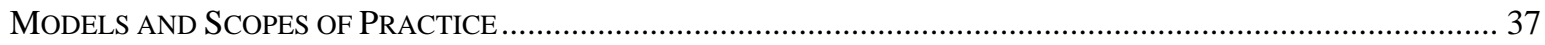

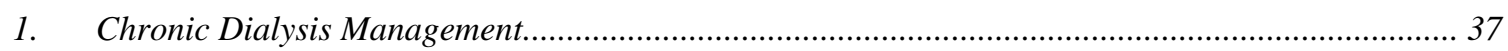

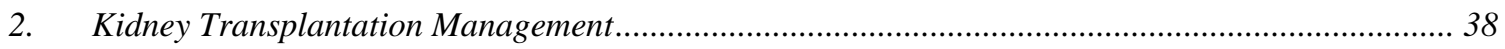

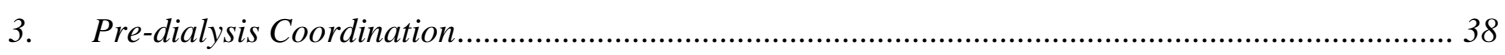

NuRSE PRACTITIONER AS AN EARLy INTERVENTIONALIST: A NEW INITIATIVE FOR NURSING.......................... 39

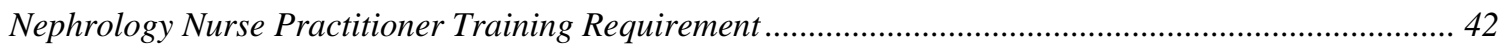

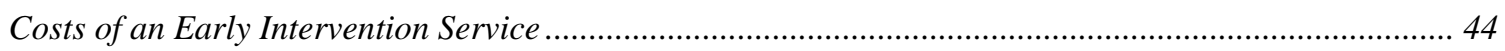

Measuring the Effectiveness of an Early Intervention Service ............................................................ 47

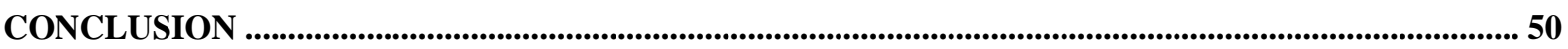

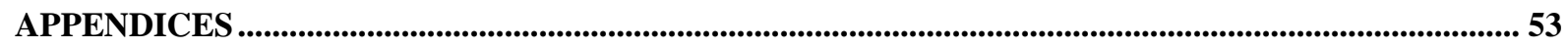

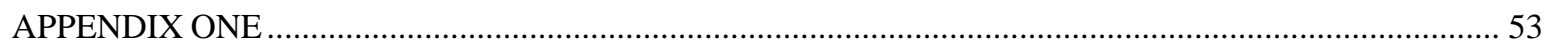

Ministry of Health: Nurse Practitioner Generic Models of Care ........................................................ 53

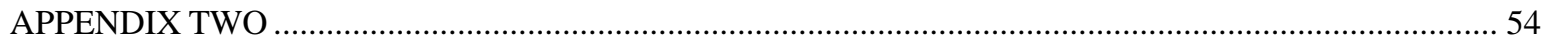

Nursing Council of New Zealand Competencies for the Nurse Practitioner............................................ 54

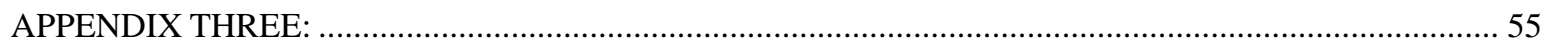

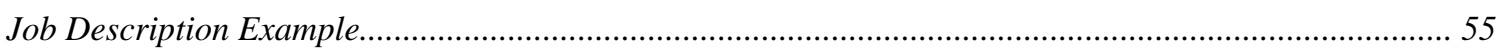

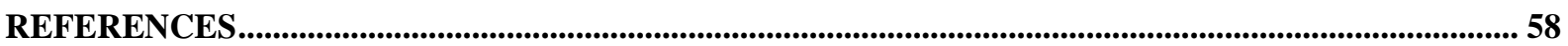




\section{LIST OF TABLES}

Table 1: Causes of Chronic Kidney Failure in New Zealand 2002 ............................................................. 6

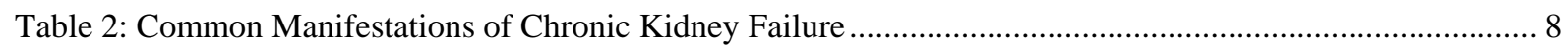

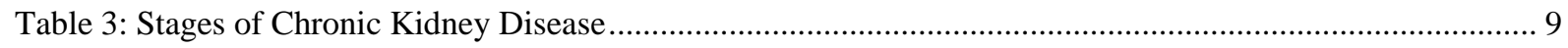

Table 4: Summary of Management Strategies for Slowing Progression of Kidney Disease .............................. 25

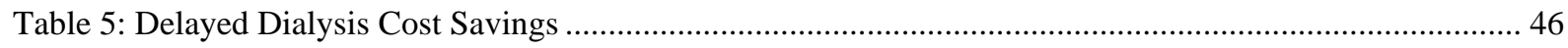

\section{LIST OF FIGURES}

Figure 1: Method for Estimating Creatinine Clearance Source: Australian and New Zealand Dialysis and

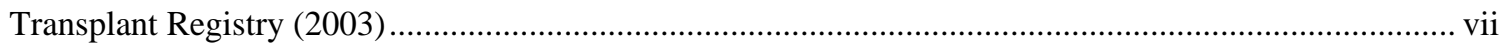

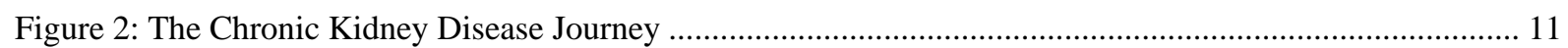

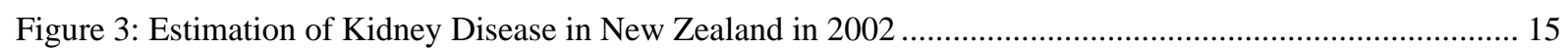

Figure 4: An Early Intervention Service for Chronic Kidney Disease ......................................................... 41 


\section{DEFINITIONS}

\section{End Stage Renal Disease (ESRD) or End Stage Kidney Failure (ESKF)}

A term used to describe the concluding stages of kidney failure, when haemodialysis, peritoneal dialysis or kidney transplantation becomes necessary to survive (Thomas \& Mathew, 2000).

\section{Chronic Kidney Disease (CKD) or Chronic Renal Failure (CRF)}

Defined as either kidney damage or glomerular filtration rate less than $60 \mathrm{ml} / \mathrm{min}$ for three months or more. This is usually a progressive process that results in end stage kidney failure (Parmar, 2002).

\section{Pre-Dialysis Period}

The spectrum of chronic kidney disease that extends from the point where there is only slight kidney damage to end stage kidney failure where commencement of renal replacement therapy is required to survive (St Peter, Schoolwerth, McGowan, \& McClellan, 2003)

\section{Renal Replacement Therapy}

Encompasses haemodialysis, peritoneal dialysis and kidney transplantation.

\section{Haemodialysis}

The process of extracoporeal filtration of blood, via a semi-permeable membrane, of waste substances that are carried away by dialysis fluid. The process requires the patient to be attached to a machine for prolonged periods of time (approximately five hours, three times a week).

\section{Peritoneal Dialysis}

A process where the peritoneal membrane is used as a semi-permeable membrane to filter waste substances from the blood. A catheter, placed in the lower part of the abdomen, allows inflow and outflow of dialysate fluid in the peritoneal cavity. The fluid in the peritoneal cavity is exchanged approximately four times a day, usually by the patient at home. 


\section{Glomerular Filtration Rate (GFR)}

GFR is the standard for determining kidney function. It is measured by the volume of fluid filtered by the kidneys per unit of time. In an average $70 \mathrm{~kg}$ adult, the normal GFR is approximately 125 milliliters per minute. For practical purposes, calculated creatinine clearance is used as a correlate of GFR and is commonly estimated by using the CockcroftGault formula as detailed in Figure One (Australia New Zealand Dialysis and Transplant Registry, 2003).

\section{Cockcroft-Gault formula: (Glomerular filtration rate) in $\mathbf{m l} / \mathbf{m i n} / 1.73 \mathbf{~ m}^{2}$}

Creatinine clearance $=(140-$ age $)($ weight* in kilograms $) \times(0.85$ if female $)$ Serum creatinine $(\mathrm{mmol} / \mathrm{l}) \times 0.81$

*The weight term used is calculated using the equation:

Lean Body Weight $=(0.9 \times$ [height -152$]+(50$ if male, 45.5 if female $)$

Figure 1: Method for Estimating Creatinine Clearance

Source: Australian and New Zealand Dialysis and Transplant Registry (2003) 


\section{INTRODUCTION}

I am a New Zealand trained registered nurse with 23 years experience in nephrology nursing. Most of that time I worked in Sydney, Australia and more recently (in the past three years) I have been practicing in the New Zealand nephrology health care environment. I began my career in nephrology nursing in 1981 when I became involved with caring for patients receiving haemodialysis and peritoneal dialysis. I have subsequently spent the majority of my nursing career working with adult patients along the continuum of chronic kidney disease. This has included acute illness episodes prior to and during end stage kidney failure, chronic kidney failure, haemodialysis, peritoneal dialysis, transplantation and palliatively when renal replacement therapy (RRT) ceases to be beneficial to the patient.

This paper has allowed me to explore a new area of nephrology nursing; an area that I believe nursing could make a positive contribution to, that of early intervention in kidney disease. The question I have raised is 'Can the expert nephrology nurse contribute to slowing the progression of kidney disease and improve patient outcomes?' Through a combination of literature critique, discussion with colleagues and personal experience I am confident the answer to this question is yes.

The issue of preventing the progression of kidney disease is more relevant now than it used to be in the 1980s because of the increase in disease presentation and the greater demand for treatment. Diabetic kidney disease has been primarily responsible for the increase in the number of new patients requiring renal replacement therapy. There is also greater demand for treatment because improved technology and advances in disease management have allowed older, sicker patients access to renal replacement therapies. In the past, only the relatively fit and young were able to receive dialysis or transplantation but now there is an expectation from the general public that treatment is provided to everyone who wants it.

As a consequence, the overall dialysis population has grown steadily causing unprecedented stress on the health care budget along with significant ethical dilemmas regarding quality of life and rationing of resources (Collins, 1998; Redman, Hill, \& Fry, 1997; Renal Physicians Association and American Society of Nephrology, 2000). In addition to coping with current patient numbers, there are strong predictions that the situation is going to get worse.

The number of people with early kidney disease is estimated to be many times more than those who are already receiving treatment. 
It seems inevitable that there needed to be a change in focus to earlier diagnosis, reduction in complications, and avoidance or delay of renal replacement therapy. Research has supplied health care providers with evidence that early detection, patient education and ongoing management of kidney disease can slow disease progression and reduce the number of new patients requiring renal replacement therapy (Knight, 2002; Levin, 2001; Levin et al., 1997; Parmar, 2002; White et al., 2002). While the concept of screening populations at risk of kidney disease and providing appropriate, ongoing care is acknowledged as worthwhile there are challenges to overcome to achieve this.

The first challenge is the development of a screening programme on a national level that identifies high-risk groups in the community with early signs of kidney disease. Once identified, the next challenge is to plan and adequately resource a disease management programme to reduce the morbidity and mortality associated with chronic kidney disease. The nephrology health care team need to work together to develop innovative ways to address these challenges. This can only be attained by mutual respect and utilisation of the unique knowledge and skill each group of healthcare professionals bring to the situation. Nursing has an opportunity to be proactive and creative by becoming involved in screening and early intervention programmes. The nurse practitioner role is an ideal framework for the development of disease management initiatives whereby nurses could work independently with patients in a supportive and collaborative environment.

The current shortage of nephrologists in New Zealand has also added weight to the argument that a nurse practitioner service could be a valuable component in an early intervention strategy. Highly skilled nephrology nurses have worked in advanced roles in the areas of haemodialysis, peritoneal dialysis and transplantation for many years. It is now time to look to the future needs of the renal community and recognise the importance of intervention during the early stages of kidney disease (Baker \& Thomas, 2001; Compton, Provenzano, \& Johnson, 2002).

Despite advances in technology and improved management of patients with end stage kidney failure, renal replacement therapy remains an expensive, relentless and rigorous treatment with high morbidity and mortality rates. I feel heartened by research that shows it is possible to reduce the number of patients progressing to end stage kidney failure and improve the outcome for those who do end up needing dialysis or transplantation. 
In New Zealand we have the benefit of drawing from international experience where there are evidence based, international guidelines already written regarding managing chronic kidney disease including early detection strategies. In addition, the many years of nurse practitioner experience in the United States of America, United Kingdom and Canada was an invaluable resource when looking to develop similar roles in New Zealand. It is timely and appropriate to consider extending nursing practice into early kidney disease management in New Zealand. Implementation will need to be well planned, collaborative and provide a positive effect on quality and effectiveness of care to be accepted by health care providers.

This paper explores nursing practice as an early intervention management strategy in chronic kidney disease. It is presented in four sections, followed by a conclusion to sum up the key factors put forward in the paper. The first section provides a background on chronic kidney disease and its impact on the New Zealand population. Following on from this, in Section Two, is a commentary on detection and management of chronic kidney disease. In this section, I have developed a set of broad best practice initiatives for the early management of kidney disease based on an extensive search of the literature. These best practice initiatives are redirected in Section Three from a symptom-focussed perspective to the construction of a 'human' picture where two case scenarios reveal the significant difference that early intervention can make on health care costs and the quality of life for the patient and their families. Section Four builds on the argument for developing early intervention programmes to combat chronic kidney disease by proposing that nephrology nurses could play a significant role in the provision of an early intervention service in New Zealand. The conclusion of the paper draws together the four sections in a summary that identifies the key factors that shape the argument for creating a nursing role in the early intervention of chronic kidney disease. 


\section{SECTION ONE: KIDNEY DISEASE AND ITS IMPACT ON NEW ZEALANDERS}

In order to appreciate the complexity and consequences of chronic kidney disease, the first section of this paper provides background information on kidney function and the causes of kidney disease. Of particular concern in this discussion is the increasing incidence of kidney disease caused by the rise in type two diabetes and predictions of how this will affect health care in the future. Kidney disease and kidney failure affect every organ in the body causing the patient to experience many symptoms during the course of their illness. An overview of the symptoms commonly seen in kidney disease illustrates the devastating effects of this chronic illness.

This section also discusses a recent classification system, developed by the American National Kidney Foundation (2002), that categorises the loss of kidney function as the disease progresses. Agreement on a standard way of defining chronic kidney disease was seen as a key factor in providing effective intervention in the future (Parker et al., 2004). The classification system described in this section has been used in some recent literature and appears likely to become the universally acceptable definition of chronic kidney disease. Following on from the classification of kidney disease is a description of the journey a person commonly takes during the time that they live with this disease. This description puts the disease as a whole into perspective and illustrates the ongoing challenges an individual faces at different stages during their chronic illness.

Included in this section is a brief epidemiological report with some discussion around the reasons for the increase in patients presenting with end stage kidney failure requiring renal replacement therapy. There are some surprising figures on the estimated number of people in this country with a degree of kidney dysfunction. This raises further questions about the significance of these figures in terms of disease management initiatives in the future. 


\section{Kidneys and Loss of Function}

\section{Functions of the Kidney}

The kidneys are responsible for maintaining the body's fluid environment in a constant and homeostatic state. The kidneys filter metabolic wastes, toxins and excess ions and fluid from the blood stream while returning needed substances to the blood. While the kidneys perform these functions they simultaneously regulate the volume and chemical makeup of the blood, maintaining the correct balance between water and salts and between acids and bases. The kidneys have other regulatory functions as well. They produce the enzyme renin, which helps regulate blood pressure and kidney function and the hormone erthyropoietin, which stimulates red blood cell production in bone marrow. The kidneys also metabolise vitamin $\mathrm{D}$ to its active form (Parker, 1998).

\section{Causes of Kidney Failure}

Kidney failure is commonly classified as an acute or chronic condition. Acute kidney failure is a temporary loss of kidney function and is often due to a short-term incident such as trauma, hypovolaemia, sepsis, obstruction or a reaction to a toxic effect of a medication, for example, certain antibiotics, non-steroidal anti-inflammatory drugs or intravenous contrast agents (Stigant, Stevens, \& Levin, 2003). Acute kidney failure is most often seen in acute care facilities, with an overall incidence of approximately 2-5\% of hospitalised patients. Acute kidney failure is frequently a reversible condition but in some instances it can lead to chronic kidney failure (Parker, 1998). The management of patients with acute kidney failure is separate to that of chronic kidney disease. Discussion of this condition is not relevant to this paper.

Chronic kidney disease (CKD) is by far the main cause of kidney failure in New Zealand and is increasing at an alarming rate each year. Diabetic nephropathy, a complication of diabetes mellitus, is the major cause of end stage kidney failure in the Western world (Walker \& Manning, 1999). This reflects the situation in New Zealand where diabetic nephropathy was responsible for almost half of the 453 new patients entering renal replacement programmes in 2002 (Australian and New Zealand Dialysis and Transplant (ANZData) Registry, 2003). Of particular concern is the disproportionately high representation of Maori and Pacific Islanders in this new patient group (Health Funding Authority, 2000; Walker \& Manning, 1999). 
Table One is a summary of the number of people in New Zealand that presented with end stage kidney disease in 2002 and the underlying cause of their disease (ANZData Registry, 2003).

Table 1: Causes of Chronic Kidney Failure in New Zealand 2002

\begin{tabular}{|l|l|l|}
\hline Disease & Patient Numbers & $\begin{array}{l}\% \text { of Total Number } \\
\text { of New Patients }\end{array}$ \\
\hline Diabetic Nephropathy & 203 & $45 \%$ \\
\hline Glomerulonephritis & 106 & $23 \%$ \\
\hline Hypertension & 39 & $9 \%$ \\
\hline Polycystic Kidneys & 19 & $4 \%$ \\
\hline Reflux Nephropathy & 16 & $4 \%$ \\
\hline Miscellaneous & 50 & $11 \%$ \\
\hline Uncertain Diagnosis & 18 & $4 \%$ \\
\hline
\end{tabular}

Glomerulonephritis, a disease that affects the tissue of the kidney, had up until recently been the most common cause of kidney disease. However, it has been overtaken by the increase in diabetes that accounted for 203 new patients diagnosed with end stage kidney failure or $45 \%$ of the total patient group. Hypertension, polycystic kidney disease and reflux nephropathy were responsible for a further $17 \%$ of the new patient population requiring renal replacement therapy in 2002.

Despite the many different causes of this disease, the signs, symptoms, and progression are similar. Occasionally, end stage kidney disease can occur suddenly as a complication of trauma or a rapidly progressing kidney disease. In these cases, dialysis is required on an emergency basis. However, in most instances, kidney disease progresses over a period of many years and is commonly known as the 'silent killer'. The diagnosis is often delayed because the signs, symptoms and metabolic abnormalities are insidious and non-specific (Stigant, et al., 2003; Szromba, Thies, \& Ossman, 2002).

Kidney disease is often picked up inadvertently by the patient's general practitioner, cardiologist, diabetiologist, community nurse or diabetic nurse educator as a consequence of an associated disorder, for example, anaemia or cardiac disease. Diagnosis is made by testing the urine for the presence of protein. 
If protein is detected, a blood test is performed to measure a person's glomerular filtration rate which is considered the best method to ascertain overall kidney function (Levey, Coresh, Balk, \& Kausz, 2003). It is important to remember that a patient can have significant kidney damage (more than 50\%) before clinical symptoms develop (Thomas \& Mathew, 2000). These symptoms relate to fluid, electrolyte, and acid-base imbalances, disordered regulatory functions, and the multisystem complications associated with uraemia.

\section{Manifestations of Chronic Kidney failure}

The kidneys are responsible for the highly complex task of maintaining homeostasis in the body; it is therefore not surprising that kidney failure has a huge impact on the overall health of a person. Kidney failure causes many physical and psychological symptoms, often over many years. Table Two provides a summary of the most common problems experienced in kidney disease. This summary provides a picture of the devastating impact kidney disease has on the major organs of the body. Of these, heart disease is responsible for the majority of deaths in chronic kidney disease patients (ANZData Registry, 2003; Pereira, 2000).

In addition, Table Two highlights the specific aspects of chronic kidney disease that have been targeted by researchers as areas where early intervention could provide an improvement in patient outcomes. The literature that addresses the main problems experienced by patients with chronic kidney disease has been critiqued in section two of this paper.

Table Two describes a vast array of symptoms that a patient can experience during the course of chronic kidney disease. Symptoms occur at different periods, and may come and go depending on individual circumstances and the level of kidney function. This variability has caused much confusion in the literature about how the progressive loss of kidney function should be measured. Some researchers want to have a clear set of stages that describe early kidney disease through to end stage kidney failure (Levey et al., 2003). Recently, the American National Kidney Foundation has attempted to define and classify this complex disease into stages that are based on the glomerular filtration rate of the kidneys (National Kidney Foundation, 2002). 
Table 2: Common Manifestations of Chronic Kidney Failure

\begin{tabular}{|c|c|}
\hline Problem & Manifestations \\
\hline $\begin{array}{l}\text { Fluid \& Electrolyte } \\
\text { Imbalance }\end{array}$ & $\begin{array}{l}\text { - Pulmonary oedema, weight gain, hypertension, pleural } \\
\text { effusion. } \\
\text { - Cough, dyspnoea, periorbital oedema, peripheral oedema, } \\
\text { congestive heart failure. } \\
\text { - High or low levels of serum sodium, potassium, calcium, } \\
\text { phosphate, magnesium and associated complications. }\end{array}$ \\
\hline Uraemia & $\begin{array}{l}\text { - Headache, drowsiness, confusion, memory loss, insomnia, } \\
\text { - } \quad \text { Paresthesias, muscle twitching, restless leg syndrome, gait } \\
\text { abnormalities, hearing loss, decreased cough reflex. } \\
\text { - } \quad \text { Pericarditis, cardiac arrhythmia, cardiac tamponade. } \\
\text { - Increased susceptibility to infection. } \\
\text { - Increased bleeding tendency, epistaxis, ecchymosis. } \\
\text { - Pruritus, dry skin, skin colour changes, pallor. } \\
\text { - Nausea, vomiting, constipation, anorexia, metallic taste in } \\
\text { mouth, gingival hyperplasia, gastritis, diarrhoea. }\end{array}$ \\
\hline Anaemia & $\begin{array}{l}\text { - Fatigue, pallor, decreased appetite, cold intolerance, } \\
\text { hypotension, reduced exercise tolerance. } \\
\text { - Shortness of breath, hypoxia. } \\
\text { - Tachycardia, increased angina, left ventricular hypertrophy, } \\
\text { heart failure. }\end{array}$ \\
\hline Cardiovascular Disease & $\begin{array}{l}\text { - Hypertension, ischaemic heart disease, congestive heart } \\
\text { failure, atherosclerosis, cardiac arrthymias, cardiomyopathy, } \\
\text { heart failure, cardiac arrest. }\end{array}$ \\
\hline Lipid Disorders & $\begin{array}{l}\text { - Cardiovascular disease, elevated triglyceride levels, elevated } \\
\text { cholesterol levels. }\end{array}$ \\
\hline Acid Base Imbalance & $\begin{array}{l}\text { - Metabolic acidosis or alkalosis, confusion, nausea, vomiting, } \\
\text { hyperkalaemia, hyperventilation, convulsion, cardiac arrest. }\end{array}$ \\
\hline $\begin{array}{l}\text { Calcium \& Phosphate } \\
\text { Imbalance \& Bone } \\
\text { Disease }\end{array}$ & $\begin{array}{l}\text { - Bone pain, pathological fractures, metastatic calcification. } \\
\text { - Hyperphosphatemia, secondary hyperparathyroidism, renal } \\
\text { osteodystrophy. }\end{array}$ \\
\hline Malnutrition & $\begin{array}{l}\text { - Weight loss, anorexia, low serum albumin, muscle wasting, } \\
\text { poor healing, susceptible to infections. }\end{array}$ \\
\hline Endocrine Disorders & $\begin{array}{l}\text { - Hypothyroidism, impotence, dysmenorrhoea, amenorrhoea, } \\
\text { decreased libido. } \\
\text { - Glucose intolerance, hypertension, hyperparathyroidism. }\end{array}$ \\
\hline Psychosocial problems & $\begin{array}{l}\text { - } \\
\text { - Lepression. } \\
\text { - } \text { Job loss / reduced employment opportunities. } \\
\text { - } \quad \text { Loss of income. } \\
\text { - } \text { Change in family dynamics / community standing. }\end{array}$ \\
\hline
\end{tabular}




\section{Classification of Kidney Disease}

The level of kidney function in all patients with chronic kidney disease can be uniformly measured regardless of the underlying cause of the disease (Levey et al., 2003). In the past, there has been a lack of agreement on how the progression of chronic kidney disease should be defined and classified. This has been said to have contributed to under-diagnosis and under-treatment of early kidney disease resulting in lost opportunities for slowing or preventing the progression of the disease (Levey et al., 2003; National Kidney Foundation, 2002; St Peter et al., 2003; Pereira, 2000).

In the literature, it is widely agreed that starting treatment at the right point in the progression of chronic kidney disease (CKD) is essential to help slow progression and prevent adverse outcomes (Knight, 2002; Levey et al., 2003; National Kidney Foundation, 2002; St Peter et al., 2003; Pereira, 2000). In an attempt to reach a consensus and provide a common ground on which to base future treatment and research, the American National Kidney Foundation's Kidney Disease Outcomes Quality Initiative work group developed a classification system that separated the period from very early kidney disease to end stage kidney failure into five stages (see Table Three) (National Kidney Foundation, 2002). Definitions were based on renal function as measured by the patient's glomerular filtration rate (GFR). Normal kidney function is said to equate to a glomerular filtration rate of 120-125 millilitres per minute with deterioration in kidney function correlating with a reduction in the glomerular filtration rate. Table Three describes the five stages of chronic kidney disease.

Table 3: Stages of Chronic Kidney Disease

\begin{tabular}{|l|l|c|}
\hline Stage & Description & $\begin{array}{l}\text { Glomerular Filtration Rate } \\
(\text { GFR ml/min/ 1.73m²) }\end{array}$ \\
\hline 1 & Kidney damage with normal or increased GFR & $>90$ \\
\hline 2 & Kidney damage with mild decrease in GFR & $60-89$ \\
\hline 3 & Moderate decrease in GFR & $30-59$ \\
\hline 5 & Severe decrease in GFR & $15-29$ \\
\hline
\end{tabular}


Stage One of chronic kidney disease (CKD) is described as the very early period of the disease where only minor kidney damage has occurred. There are usually no clinical symptoms at this point, which makes diagnosis very difficult. This is the ideal time to provide treatment for the underlying kidney disease, along with appropriate management of associated conditions such as hypertension and diabetes. Patients who are classified as Stage Two CKD have a glomerular filtration rate of between 60 and $89 \mathrm{ml} / \mathrm{min} / 1.73 \mathrm{~m}^{2}$ and suffer from a mild degree of kidney damage. Aggressive management of the underlying causes of the disease and emerging manifestations, for example, calcium and phosphate imbalance, hyperglycaemia and anaemia, are recommended (St Peter et al., 2003; Silverberg, 2003).

Stage Three CKD indicates a further decline in kidney function with possibly some clinical signs beginning to appear. As mentioned previously, it is not uncommon for a patient to reach this stage of the disease without knowing that they have a problem. Again ongoing specialist treatment and follow up of these patients is essential to try and maintain kidney function and prevent such complications as cardiovascular disease, anaemia, malnutrition and bone disease. Stage Four of chronic kidney disease means that end stage failure is imminent and preparation for renal replacement therapy is required. Stage Five CKD is defined as end stage kidney failure where renal replacement therapy is required to sustain life.

The reason the American National Kidney Foundation developed the five-stage classification system was to provide a common language for communication among providers, patients and their families, investigators and policy-makers. Defining chronic kidney disease provides opportunities to direct the most effective treatment at a particular stage of the disease process (Compton et al., 2002).

Classification also aims to provide a framework for developing clinical practice guidelines, clinical performance measures, and continuous quality improvement efforts (Parker et al., 2004). The American National Kidney Foundation's classification of the stages of kidney disease has been incorporated in some recent American and British literature in relation to strategies for prevention and early detection of chronic kidney failure (Compton et al., 2002; St Peter et al., 2003; Parmar, 2002). As this classification system has only been available for two years it is difficult to predict the extent to which it will be utilised internationally. 
In summary, the function of the kidneys and the consequences of kidney failure have been outlined along with a way of defining the loss of kidney function into stages. The five stages of chronic kidney disease, as described in Table Three, were developed in an attempt to provide a common language for nephrology health care professionals to use to promote international best practice in the management of CKD.

Although this paper focuses on the early stages of chronic kidney disease, there are many challenges for individuals once they progress past Stage Five CKD to total loss of kidney function where renal replacement therapy is required to stay alive. Renal replacement therapy is a rigorous and relentless treatment that often has an unpredictable course. The medical, social and economic repercussions of CKD are widespread and span the entire spectrum of the disease. The CKD disease spectrum is presented to illustrate that the patient has to cope with continual change during the course of this illness, from the early stages through to the prospect of a premature death.

\section{The Chronic Kidney Disease Journey}

Chronic kidney disease is often described as a journey for the patient because of the ongoing changes that occur as kidney function is lost, and decisions about life saving treatments are required. Figure Two provides an overview of how the progression of the disease spans out over many years in a person's life.

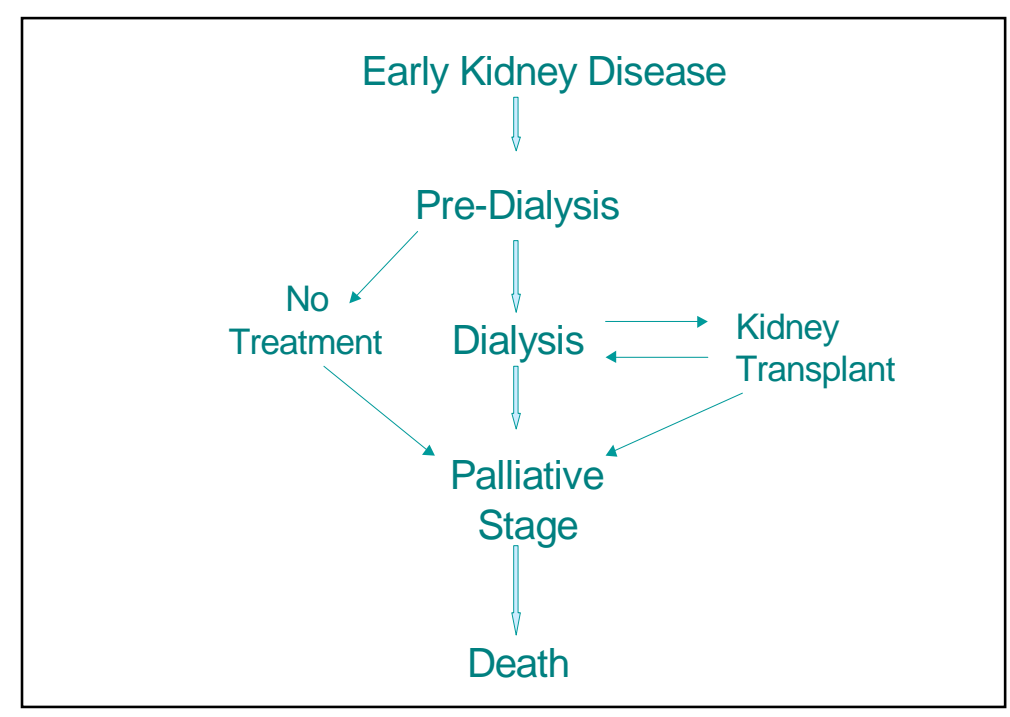

Figure 2: The Chronic Kidney Disease Journey 
It begins with Stages One to Five CKD as described in Table Three. Early kidney disease could be defined as Stages One to Three CKD where the damage to the kidneys may progress undetected for some time as signs and symptoms are not yet apparent. Individuals with kidney disease at this time often feel well and find it difficult to comprehend the long-term consequences of the disease. However, as kidney function continues to decline the predialysis phase or Stages Four and Five CKD begins to impact on the health and wellbeing of the patient. At this point, end stage kidney failure is the most likely outcome therefore individuals are faced with the need to make decisions about their future health care management. There can be several different options to consider, they may choose not to have any renal replacement therapy, in which case conservative treatment is provided. Some patients are given the option of accepting a live donor kidney transplant, even before they reach the point where dialysis is required. This option is most often open to paediatric patients, with a parent providing the donor kidney to their child to prevent them from having to start on dialysis therapy.

Accepting the opportunity to commence dialysis therapy is the other option available and one that most patients choose. There are two types of dialysis, haemodialysis and peritoneal dialysis. The patient and their families, with the support and advice of the nephrology health care team, make the final decision about what type of dialysis they want. A patient having dialysis therapy may receive a kidney transplant from a cadaver or live donor if they are assessed as medically fit. Transplantation is a form of renal replacement therapy that always has the potential to be rejected by the patient's body. If a transplanted kidney fails, the patient will again require dialysis to stay alive. A patient may have more than one kidney transplant in their lifetime, giving them periods where they are free from needing dialysis therapy. Unfortunately, chronic kidney disease is a terminal condition and patients will ultimately require palliative care as they reach the end of their journey. The kidney disease journey as shown in Figure Two is often spread out over many years with patients and their families living in a constant environment of uncertainty and the possibility of a pre-mature death (Polaschek, 2003).

The life long effects of chronic kidney disease on the individual and their families are significant. The renal replacement therapy choices currently available do not provide a cure for kidney disease and continue to cause high morbidity and mortality in the end stage kidney disease population. 
Optimising the health of individual suffering from CKD during the early stages of this journey offers the possibility of an improved quality of life, fewer complications and a reduction in health care costs across the entire disease continuum. The extent to which CKD effects the New Zealand population is examined in the next section with predictions of an alarming escalation in the number of individuals presenting with end stage kidney failure.

\section{Epidemiology}

The New Zealand nephrology community is fortunate to have the Australian and New Zealand Dialysis and Transplant Registry (ANZData Registry) as an epidemiological reference. The ANZData Registry is a comprehensive and detailed account of the delivery of dialysis and transplantation services in Australia and New Zealand. The 2003 report is the Registry's $26^{\text {th }}$ annual report that includes data collected up until $31^{\text {st }}$ December 2002 . The Registry provides an excellent source of information and is used regularly in Australasian publications. All nephrology departments in Australia and New Zealand contribute to the Registry.

In New Zealand the number of patients entering a renal replacement therapy programme increased by seven percent in 2002, and has been increasing at around seven to nine percent for the last ten years. At the end of 2002, 1586 patients were receiving either peritoneal or haemo dialysis and there were 1114 people with functioning kidney transplants in the community. During the year of 2002 there were 453 new patients started on renal replacement therapy. Of particular note are the $27 \%$ of new patients who were referred late to nephrological care that is, less than three months before first treatment. Late referral patients are more likely to require emergency dialysis treatment and have a higher morbidity and mortality rate than those patient who have been prepared for end stage kidney failure (Parmar, 2002; Pereira, 2000; Stigant et al., 2003). If the growth rate of dialysis patients continues at seven to nine percent a year then by 2013 there will be 3896 individuals receiving dialysis in New Zealand, an increase of $141 \%$ over a ten year period. 
Kidney transplantation in New Zealand remains low with only 117 transplants performed during 2002, 41\% were live donor transplants, a slight increase from previous years. The small increase in live donor transplantation over the past eight years is due to the introduction of unrelated live donor transplantation, mainly husband or wife as donors. There were 320 patients waiting for a kidney transplant at the end of March 2003, which represents 20\% of the dialysis population. There have been efforts over the years to increase kidney transplantation. As recently as February 2004 the Health Minister, Annette King, proposed a national organ donation agency in an attempt to increase the organ donation rate (King, 2004). The low transplantation rate is however not the main reason why the end stage kidney disease population and dialysis numbers are rising. Improvements in dialysis technology and pharmacology, and broadening of clinical expertise make it possible to dialyse older and sicker patients. This is evident in the ANZData figures where the over 65-year-olds made up $27 \%$ of new patient starting treatment in 2002.

Most of older and sicker patients are not suitable for a kidney transplant because they would not survive the rigours of the surgery and subsequent life-long anti rejection therapy. In addition, the rapid rise in diabetes and the associated complication of kidney failure has become a major concern not only in New Zealand but is a worldwide health care problem (Ritz, 2001). In 2000, the New Zealand Health Funding Authority reported that there were 115,000 people with known diabetes in New Zealand, and a possible 40,000 to 60,000 people undiagnosed.

The Ministry of Health's epidemiological model predicts that the incidence of diabetes will double by 2011 resulting in an escalation of associated co-morbidities including heart and kidney failure (Ministry of Health, 2000). The Health Funding Authority 2000 report also highlighted that Maori and Pacific Island people are three times more likely to have diabetes than other New Zealanders. Consequently, the dialysis acceptance rates for Maori and Pacific Islanders is three and a half times that of the rest of the population. They constitute almost half of all dialysis patients in New Zealand (ANZData Registry, 2003; Collins, 1998). 
There is similar concern in the international literature about the impact of diabetes and the growth of end stage kidney failure. It has been recognised that there are a large number of undiagnosed and untreated individuals in the community who have mild kidney damage caused primarily by diabetes. They need to be identified and managed appropriately to prevent the increase in the end stage kidney failure population (St Peter et al., 2003).

A Canadian nephrologist, Malvinder Parmar, highlighted this point when he wrote an article in the British Medical Journal stating that 'for every patient requiring renal replacement there are 20 to 30 others in the community with some degree of kidney dysfunction' (Parmar, 2002, p.85). If Parmar's estimations were translated into the New Zealand context, the number of people with some degree of kidney disease would be estimated at 54,000 to 81,000 . Figure Three illustrates that the end stage kidney disease population of 2700 in 2002 was just the 'tip of the iceberg', with up to 81,000 others who could potentially develop significant kidney disease in the future. These figures emphasise the need to develop strategies to detect and manage kidney disease before the need for renal replacement therapy arises.

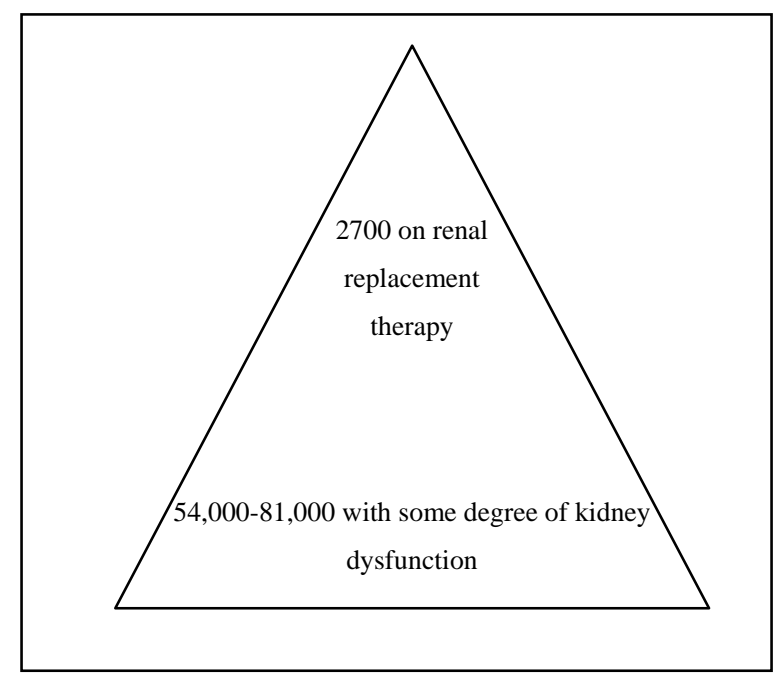

Figure 3: Estimation of Kidney Disease in New Zealand in 2002

In summary, Section One has acknowledged that the kidneys are vital for the maintenance of homeostasis in the body. When they are compromised due to various disease processes, the impact is felt by the whole body causing chronic, debilitating ill health. Researchers have sought a way to define the progression of chronic kidney disease by classifying levels of kidney function into stages. The hope is that each stage will have specific treatment strategies designed to maximise kidney function and minimise complications. Once the glomerular filtration rate has fallen below $15 \mathrm{ml} / \mathrm{min}$ (Stage Five) a person can no longer survive without some form of renal replacement. 
Although chronic kidney disease is described in stages in the literature, it is a continuous journey for the patient. The patient faces many challenges and treatment decisions as their kidney disease progresses. Unfortunately, there is a time in this journey where available treatment does not provide any further benefit to the patient and palliative care is required.

Chronic kidney disease has been shown to be effecting more New Zealanders each year and is of concern to health care professionals working in this specialty. The increase in diabetes in New Zealand clearly reflects the worldwide diabetic epidemic. The New Zealand government is aware of the increase in diabetes but has not indicated that the associated complication of kidney disease is a separate and serious issue requiring urgent attention. There is still a focus on treating end stage kidney failure rather than trying to prevent it.

The international literature is turning its attention to the large number of people in communities who have minimal kidney damage. There are opportunities to identify the highrisk groups and detect this disease early enough to delay and even prevent the need for expensive, life saving treatment. The next section of this paper looks at the early detection of kidney disease and discusses how best to manage specific aspects of kidney disease based on available evidence. 


\section{SECTION TWO: MANAGEMENT OF CHRONIC KIDNEY DISEASE}

Section One has backgrounded the state of chronic kidney disease and looked at where it is heading in the future. The growth predictions and consequences of kidney disease have provided health care professionals with a sound argument for putting more energy into early management initiatives. In Section Two I present a commentary on the detection and management of kidney disease. Many published studies have examined the best way to manage specific aspects of chronic kidney disease to preserve kidney function and minimise complications. Countries such as the United States of America, Canada and Australia have developed guidelines for kidney disease management after systematically reviewing the literature (Caring for Australians with Renal Impairment (CARI) Guidelines, 2004; Churchill et al., 1999; National Kidney Foundation, 2002). The guidelines, along with other research were reviewed. A summary of the specific areas of disease management that came out of the literature as positively influencing the progression of kidney disease will be presented. This section will progress as follows: sources and search criteria, detection of kidney disease and best practice in the management of early kidney disease. Concluding comments will complete this section.

\section{Sources and Search Criteria}

A literature review was performed that looked at detection of kidney disease and evidence relating to slowing the progression of kidney disease and preventing associated complications. To investigate the role of the nephrology nurse in kidney disease management, a further search was performed on advanced nursing practice. This was narrowed to looking at advanced nephrology nursing practice. The information found on nursing practice relates to Section Four of this paper. I searched Medline, Cinahl, Proquest and Te Puna databases from 1990 to 2004. I also obtained some information from a Google search using the key words listed.

For information on international guidelines I accessed the following websites: United Kingdom Renal Registry, Australian and New Zealand Dialysis and Transplantation Registry, United States Renal Data System, New Zealand Kidney Foundation, National Kidney Foundation Kidney Disease Outcomes Quality Initiative (K/DOQI) and CARI Guidelines. 
Key words used in the search: Chronic kidney disease, kidney failure, renal insufficiency, early detection, nurse practitioner, disease management, advanced nursing practice, nephrology nursing.

\section{Detection of Kidney Disease}

Before the symptoms of kidney disease are recognised, there is often significant deterioration in kidney function. Early stages of kidney disease can be detected through testing the urine for protein. Proteinuria is currently considered the single best predictor of kidney disease (CARI Guidelines, 2004; Parmar, 2002). A commonly used measurement of kidney function is serum creatinine levels and estimating glomerular filtration rate (GFR) which also identify reduced kidney function (National Kidney Foundation, 2002). Identifying patients with kidney disease has become an important worldwide health issue, screening high risk groups have been initiated in United States of America, South Africa, India and Singapore (Knight, 2002; Levin, 2001).

The Australian Kidney Foundation established a 'KidneyCheck’ Australia Taskforce in 2001 in response to a feasibility study which indicated that screening of high risk groups for chronic kidney disease could be beneficial and cost effective (Knight, 2002). The Australian Kidney Foundation identified six high risk groups in the local population, they were 'people with diabetes, people with hypertension, smokers, people with a family history of kidney disease, people over 50 years of age and people who enjoy an Aboriginal or Islander heritage' (Knight, 2002 p. s34). The Australian public and health care professionals, in particular general practitioners, have been exposed to an intensive education program to promote a greater awareness of kidney disease and provide proactive management strategies to improve patient outcomes.

Unfortunately there is no such initiative in New Zealand, although the high-risk groups identified in the Australian study could readily be transferable to the New Zealand context by changing the sixth high-risk group from Aboriginal or Islander heritage to Maori and Pacific Island people. The New Zealand (N.Z.) Kidney Foundation (2004) acknowledges that early detection and treatment is crucial and suggests that an individual with any of the stated risks should be checked for signs of kidney disease. 
While the N.Z. Kidney Foundation does an admirable job, with limited funds, this is an inadequate strategy from a nation that is facing a substantial increase in kidney disease in the future. The government's health strategy includes the reduction in the incidence and impact of diabetes as a population health objective but does not mention kidney failure as a separate concern (Ministry of Health, 2000). The increase in patient numbers and resource demands that are associated with early screening and intervention would require a long-term commitment from the government. Unfortunately, the political environment discourages long-term strategies where there is significant initial cost in favour of cheaper short-term solutions that produce more immediate results.

\section{Best Practice in the Management of Early Chronic Kidney Disease}

Once an individual is diagnosed with chronic kidney disease, the challenge is to slow the progression of the disease, minimise the associated risk factors and prepare the patient for end stage kidney failure. I went looking for best practice guidelines in relation to the early intervention of kidney disease in New Zealand. I discovered one article, published in 1997 (Simpson et al., 1997), that was written as a consensus document following a company sponsored meeting. A group of nephrologists attending this meeting developed a broad set of guidelines for managing progressive kidney failure 'under the headings of hypertension, diet, hyperlipidaemia and bone disease' (Simpson et al., 1997, p.421). The authors of the guidelines acknowledged that they were not definitive and would need further modification, as new evidence became known. Unfortunately, they were never developed any further, nor were they supported or acted upon by the government.

Apart from the 1997 article, there was no other literature on early intervention guidelines for chronic kidney disease in New Zealand. I therefore examined the international literature on best practice intervention strategies during the early stages of CKD. From the literature, I have identified specific aspects of disease management that have been shown to slow the progression of kidney failure and improve patient outcomes. After presenting each of these aspects of disease management independently, I developed a table that creates an easy reference set of specifications for the early management of CKD. 


\section{Chronic Kidney Disease: Specific Management Strategies}

\section{Blood Pressure}

Hypertension is a well established cause and a common complication of kidney disease. It has been shown in many studies that controlling hypertension significantly reduces the progression of kidney disease (Stigant et al., 2003). The use of angiotensin converting enzyme (ACE) inhibitors are often prescribed as first line agents as they can control high blood pressure and independently retard the progression of kidney disease (Parmar, 2002; Pereira, 2000; Ritz, 2001; Stigant et al., 2003; Thomas \& Mathew, 2000). Because of their renoprotective properties, ACE inhibitors have been reported to benefit non-hypertensive patients as well. Patients who cannot tolerate ACE inhibitors can be treated effectively with angiotensin-receptor blockers (Stigant et al., 2003). In addition, dietary sodium restriction is essential for controlling hypertension in patients with chronic kidney disease. The recommended target blood pressure should be less than 130/85 mmHg in all patients with identified kidney failure, although lower levels are advised for patients with urine protein excretion of greater than one gram in 24 hours (Parmar, 2002; Thomas \& Mathew, 2000).

\section{Blood Sugar}

For the diabetic patient, hyperglycaemia causes glomerular hyperfiltration that results in sclerotic damage to the kidney. Strict control of blood glucose using pharmacological and dietary intervention has been conclusively shown to reduce the incidence and slow the progression of diabetic kidney disease (Stigant et al., 2003). Thomas and Mathew (2000) stated that an ideal target glycerated haemoglobin is around seven percent. The fluid retention and anorexia associated with increasing uraemia make hypoglycaemia and hyperglycaemia more common and blood sugar levels harder to control. A high level of commitment from the patient and the health care team were noted in the literature to be key elements in keeping blood sugar levels within tight limits (Thomas \& Mathew, 2000; Ritz, 2001).

\section{Nutrition}

There has been controversy over the most appropriate diet for patients with chronic kidney disease. Some studies report that lowering protein intake to 0.7 to 1.2 grams per kilogram per day can slow the progression of the disease (Parmar, 2002). However, restricting protein intake in kidney failure can lead to malnutrition and poor patient outcomes. 
Alternatively eating a high protein diet prevents malnutrition but can increase proteinuria and cause further damage to the kidneys. Loss of appetite, nausea and vomiting are common in the later stages of kidney failure resulting in a spontaneous reduction in protein intake. Initiation of dialysis may be necessary, in some instances, to maintain optimal nutrition. Hence regular dietary review is essential to ensure malnutrition is avoided (Pereira, 2000; Thomas \& Mathew, 2000).

\section{Anaemia}

Anaemia in kidney failure is primarily caused by the inability of the kidneys to produce erthyropoietin, a hormone that stimulates the bone marrow to produce red blood cells to provide adequate oxygen to the body. Anaemia often occurs in the early stages of the disease process ie. from Stage Two CKD. The physiological effects of anaemia are numerous (see Table Two) and relate to the body attempting to compensate for hypoxia (Macdougall, 1998). Silverberg (2003) reports that anaemia can accelerate the progression of kidney disease and is an independent risk factor of mortality in patients with chronic kidney failure.

The development of recombinant human erythropoietin revolutionised the treatment of renal anaemia in the late 1980's when the only treatment prior to this was regular blood transfusions. In addition to administering erythropoetin, adequate iron stores are needed to sustain erythropoiesis. Oral or intravenous iron supplementation is prescribed to rectify iron deficiencies. The DOQI guidelines (National Kidney Foundation, 2002) recommendations of transferrin saturation levels greater than $20 \%$ and serum ferritin levels greater than $100 \mathrm{ng} / \mathrm{ml}$, are recognised as reasonable levels to allow good erythropoetin utilisation (Pereira, 2000). Monitoring haemoglobin, maintaining adequate iron stores and erythropoetin administration are three clearly defined and effective strategies for the prevention of anaemia in the patient with chronic kidney disease.

\section{Cardiovascular Disease}

Cardiovascular disease is given special consideration in the literature because it is responsible for the majority of deaths in patients with kidney disease (ANZData Registry, 2003; Pereira, 2000). Factors such as volume overload, anaemia, hypertension, lipid abnormalities, myocardial cell injury and endothelial cell dysfunction are often responsible for ischaemic heart disease, congestive heart failure and left ventricular hypertrophy in the early stages of chronic kidney disease (Parmar, 2002; Pereira, 2000; Silverberg, 2003; Walker, 1997). 
Recommendations in the literature encourage aggressive intervention to prevent cardiovascular disease as early as stages one and two of chronic kidney disease (Levey et al., 2003: Parmar, 2002).

\section{Hyperlipidaemia}

Lipid abnormalities may be present with only mild kidney impairment and can contribute to worsening kidney function and increased cardiovascular morbidity and mortality. The primary abnormality tends to be increased triglycerides and low-density lipoprotein cholesterol levels. The literature recommends reducing high lipid levels in high-risk populations such as people with kidney disease (Stigant et al., 2003). Non-pharmacological control through physical activity, weight loss and dietary modification are important components of the treatment regime. Studies have shown that lipid reducing medications (statins) can decrease urinary protein loss and preserve the glomerular filtration rate in patients with kidney disease (Parmar, 2002).

\section{Bone Disease}

In chronic renal failure there is a disruption of calcium and phosphate balance in the body that causes a complex sequence of events that, if left untreated, leads to bone disease and soft tissue calcification (Parker, 1998). The underlying cause of this disruption is due to the decrease in excretion of phosphate by the kidneys and their inability to produce active Vitamin D. Hyperparathyroidism has been demonstrated as early as Stage Two in chronic kidney disease and contributes to pathological bone changes (Pereira, 2000). Treatment strategies include decreasing dietary phosphate and taking medication that binds and excretes phosphate in the intestine. Oral vitamin D supplementation is also recommended to suppress high parathyroid levels (Pereira, 2000; Stigant et al., 2003).

\section{Smoking}

Smoking not only increases the chance of cardiovascular disease but is also an independent risk factor for developing end stage kidney failure in some people (CARI Guidelines, 2004). Males and diabetics are particularly susceptible to kidney disease if they smoke (Orth et al., 1998; Parmar, 2000). Cessation of smoking programs is an integral part of health promotion and disease prevention throughout the world. The literature strongly recommends that smokers with kidney failure should stop. 


\section{Referral to Nephrology Care Team}

There has been much discussion and debate in the literature regarding the best time to refer a patient to the nephrology care team. The optimal period of time to adequately prepare a patient for end stage kidney failure and minimise the complications associated with kidney disease has not been ascertained. Several studies have suggested that if a patient is referred at least three months before needing renal replacement therapy, they will have a better outcome (Cass et al., 2002; Roderick et al., 2002; Stoves, Barlett, \& Newstead, 2001). Other studies consider three months to be too short and recommend longer periods of up to 12-18 months (Parmar, 2002; St Peter et al., 2003; Simpson et al., 1997; Stigant et al., 2003). The recent development of the American National Kidney Foundation's (NKF) five-stage chronic kidney disease classification (see Table Three) that focuses on GFR rather than a timeframe, may be a helpful tool to provide a common base for all health care providers to work from.

Some literature suggests intervention by the nephrology care team at Stage Two CKD for optimal patient outcomes (National Kidney Foundation, 2002; Parmar, 2002). Despite the uncertainty around patient referral time there is strong support that specialist nephrology intervention prior to end stage kidney failure is beneficial to patient outcomes. (Holland, \& Lam, 2000; Knight, 2002; Levin, 2001; Mendelssohn et al., 1999; Parker et al., 2004; Parmar, 2002; Stigant, Stevens \& Levin, 2003; Thomas \& Mathew, 2000).

\section{Education}

The implementation of treatment strategies alone is unlikely to be effective in preventing the progression of kidney failure. If a patient is not experiencing any symptoms of the disease, it may be difficult for them to come to terms with their diagnosis (Challinor \& Sedgewick, 1998). A programme of education is required to ensure that patients understand the seriousness of their condition and adhere to the treatment regime.

Different types of education sessions described in the literature were individual teaching with patients and their families, group sessions, written material, videotapes and discussion with patients already on dialysis. Obrador and Pereira (1998) found that an informed patient is more likely to monitor their condition and adhere to prescribed dietary and medication requirements. This study also showed that pre end stage kidney failure patients who had made an informed decision, under non-emergency circumstances, were less likely to change their dialysis modality (haemodialysis or peritoneal dialysis). 
Other benefits of an education programme included more patients choosing peritoneal dialysis (a cheaper form of dialysis than haemodialysis), continued employment after the start of dialysis, and an unexpected finding of delayed initiation of renal replacement therapy (Binik et al., 1993; CARI Guidelines, 2004; Pereira, 2000; Stephenson, 1993; Szromba, 1998).

\section{Dialysis Access}

Patients starting peritoneal dialysis require placement of a cuffed peritoneal dialysis catheter two to four weeks prior to commencement of treatment to allow healing and reduce the risk of leaking (Levin, 2001; National Kidney Foundation, 2002; Pereira, 2000). For patients who select haemodialysis, the preferred type of access is the native arteriovenous fistula, followed by arteriovenous grafts and then the use of central venous catheters (Churchill et al., 1999; Levin 2001; National Kidney Foundation 2002; Parmar, 2002; Pereira, 2000).

Ideally, each nephrology centre should have a dedicated team that manages vascular access including a nephrologist, surgeon, interventional radiologist and a nephrology nurse (Churchill et al., 1999; National Kidney Foundation, 2002). A period of three to six months to allow an arteriovenous fistula to mature before it is used is recommended in the majority of the literature, including guidelines from the United States of America, Canada and Australia (CARI Guidelines, 2004; Churchill et al., 1999; National Kidney Foundation, 2002).

The large amount of literature found on monitoring and intervention of specific aspects of CKD provided some broad themes and common management strategies. From these, I have developed a ready reference table that identifies specific areas of care that require attention, and offer a brief summary of how these treatment strategies might be achieved. 
Table 4: Summary of Management Strategies for Slowing Progression of Kidney Disease

\begin{tabular}{|c|c|}
\hline Target Areas of Care & Management Strategies \\
\hline $\begin{array}{l}\text { Blood Pressure } \\
\text { Control } \\
<130 / 85 \mathrm{mmHg}\end{array}$ & $\begin{array}{l}\text { Antihypertensives. ACE Inhibitors recommended because of additional renoprotective } \\
\text { properties. }\end{array}$ \\
\hline Blood Sugar Control & $\begin{array}{l}\text { Aim for glycerated haemoglobin is around } 7 \% . \\
\text { Diet and medications to maintain tight blood sugar control. } \\
\text { High level of patient commitment required. Ongoing patient education and support. }\end{array}$ \\
\hline Nutritional Advice & $\begin{array}{l}\text { Possible low protein diet of } 0.7-1.2 \text { gram/day. } \\
\text { Must be closely supervised by dietitian due to high risk of malnutrition. }\end{array}$ \\
\hline Blood Lipid Control & $\begin{array}{l}\text { Weight reduction, increased physical activity, dietary modification. } \\
\text { Lipid lowering agents eg. Statins. }\end{array}$ \\
\hline Prevention of Anaemia & $\begin{array}{l}\text { Iron replacement therapy (Intravenous or oral) if iron deficiency is present. } \\
\text { Maintain a target haemogloblin of 11grams/decilitre. } \\
\text { Recombinant human erythropoietin therapy. }\end{array}$ \\
\hline Smoking Cessation & Stop smoking programs. Support and education from health care professionals. \\
\hline $\begin{array}{l}\text { Referral to Nephrology } \\
\text { Care Team }\end{array}$ & $\begin{array}{l}\text { Refer at Stage } 2 \text { of chronic kidney disease (GFR } 60-89 \mathrm{ml} / \mathrm{min} \text { ) } \\
\text { Use GFR rather than timeframe for referral. } \\
\text { Some suggest } 12-18 \text { months is required to adequately prepare for end stage kidney failure }\end{array}$ \\
\hline Education & $\begin{array}{l}\text { Start education early; include patients and their families. } \\
\text { Patients must have access to staff to allow for sufficient information and education to make } \\
\text { an informed decision about treatment choices. } \\
\text { Individual patient education sessions, written material, videotapes, group sessions, } \\
\text { discussion with other patients on dialysis. }\end{array}$ \\
\hline $\begin{array}{l}\text { Timely Access } \\
\text { Placement }\end{array}$ & $\begin{array}{l}\text { Cuffed peritoneal dialysis catheter placement 2-4 weeks prior to dialysis commences. } \\
\text { Arteriovenous (AV) fistula - access of choice. } \\
\text { Use of dedicated vascular access team. } \\
\text { Ideally allow 3-6 months maturation time before AV fistula used. }\end{array}$ \\
\hline
\end{tabular}

I was pleased with the material that I located from journals and international guidelines and that I was able to generate a listing of key strategies that provide a clear set of specifications relating to early intervention in CKD. Once this project is completed, I intend to present this reference to my District Health Board and the nephrology health care team for consideration and further development of best practice guidelines. 
To conclude, this section has looked at initiatives for detecting early signs of kidney disease. It appears that other countries have taken up the challenge of screening high-risk populations. New Zealand has been slow to realise the long-term benefits gained by investing in such schemes. Once individuals are identified as having early stage kidney disease, it is vital that they are provided with appropriate and timely treatment to delay the progression of the disease and minimise associated complications.

A search of the literature revealed a great number of studies on specific aspects of chronic kidney disease management. It is clear from the literature that rigorous attention to the underlying cause of the disease and management of the associated complications could reduce the severity of the disease. Recent international guidelines from the United States of America, Canada and Australia have added weight to the evidence that shows that early intervention can improve patient outcomes.

There is consensus from researchers that the specific targeted areas of care, as described in Table Four, are the most important for slowing the progression of the disease and improving patient outcomes. The annual nine-percent growth in the end stage kidney failure population in New Zealand suggests that patients are not benefiting from the research that has been done and the recommendations that have come out of it.

The literature consistently remarked on the lack of attention that was given to the management of chronic kidney disease in the early stages. There was also an agreement that the solution to providing the necessary care to maintain kidney function and treat associated complications lies in a multidisciplinary team approach. No one group of health care professionals is able to tackle this issue alone. The benefits of the multidisciplinary approach and the management strategies discussed in this section are best argued by showing how they could be implemented in the clinical setting. Two case scenarios have been developed and presented in the next section to show how appropriate and timely intervention can significantly effect patient outcomes. 


\title{
SECTION THREE: TWO CASE SCENARIOS IN CHRONIC KIDNEY DISEASE
}

The production of best practice guidelines carries a 'symptom focussed' construction of early intervention. The people costs and health care costs generate other imperatives and considerations. I searched the literature to see if I could locate material that generated dialogue in relation to these considerations. One paper by an American nephrologist, Pereira (2000), stimulated my imagination because it presented two case scenarios that exemplified the extremes in care for patients approaching end stage kidney failure. I thought this would be helpful for this paper in the representation of early intervention in CKD. Therefore, I have taken the liberty of using these case scenarios from Pereira's article. I have modified these two 'real case' scenarios and changed the clinical indices to fit into the New Zealand context. In this section, I present these two case scenarios to show two very different human costs in relation to CKD. In addition, they reveal significant health care costs and implications.

\section{Patient Scenario One: Late Referral to Nephrology Service}

\begin{abstract}
A 56-year-old man presented to the emergency room at a city hospital in August 2004 with nausea, vomiting, haemoptysis and pulmonary oedema. He was drowsy and unsteady on his feet. A general practitioner had seen him for hypertension and renal insufficiency on a few occasions in the previous five years, but he was lost to follow-up in the last year. At presentation, his blood pressure was 170/120-mm Hg. Positive findings on examination included a pericardial friction rub, diffuse pulmonary crackles and mild oedema. Laboratory tests revealed a haemoglobin of $80 \mathrm{~g} / \mathrm{l}$; blood urea nitrogen, 65mmol/l; serum creatinine, $1500 \mathrm{mmol} / \mathrm{l}$; albumin, 30g/L; calcium $2.0 \mathrm{mmol} / \mathrm{l}$ and phosphate $3.5 \mathrm{mmol} / \mathrm{l}$. The arterial blood $\mathrm{pH}$ was 7.14; $\mathrm{pO}_{2}$ 133; $\mathrm{pCO}_{2} 12$ and bicarbonate 16mmol/l. He was admitted to the Intensive Care Unit (ICU), where an internal jugular catheter was placed and haemodialysis started. After three days in the ICU, he was transferred to the ward. He remained hospitalised for 15 days, during which his cardiovascular and fluid status were stabilised, permanent access was planned, and he underwent education regarding dialysis and the management of the complications of his chronic kidney failure. He was not eligible for the transplant waiting list due to his severe cardiovascular disease and poor overall state of health.
\end{abstract}


The first scenario describes a late referral patient with chronic kidney disease in a situation where he did not receive any intervention during the early stages of the disease process. This patient had his kidney dysfunction detected early on but failed to get the appropriate referral and follow up care that would have prevented his acute presentation. His condition on presentation reflected the multiple organ damage that had occurred as a result of his kidney failure over the previous five-year period. Some of the acute problems such as fluid overload and uraemia were relieved by emergency dialysis treatment. However, the effects of long term hypertension, oedema, anaemia, acidosis and calcium and phosphate imbalance had caused irreversible cardiovascular disease, bone disease, malnutrition and overall poor health.

He therefore faced his remaining years coping with a relentless dialysis regime and increasing complications without the prospect of ever receiving a kidney transplant. The insertion of a temporary venous catheter to access the blood for haemodialysis is an expensive procedure that carries a high risk of complication (National Kidney Foundation, 2002; Pereira, 2000). A permanent vascular access could have been created in this patient in advance in anticipation of the need for dialysis. Alternatively, the patient could have had a peritoneal catheter inserted if he had had time to consider peritoneal dialysis as his treatment of choice.

The emergency health care costs for this individual were high and avoidable. They included admission to intensive care and a further period as a ward patient, acute haemodialysis treatment and temporary vascular access. In addition, high cost dialysis therapy and treatment of complications associated with his disease would be ongoing with no possibility of receiving a kidney transplant in the future. Furthermore, and most importantly, the progression of his disease could have been delayed if early management strategies were applied. This patient could possibly have had several more years dialysis free and experienced a better quality of life, including maintaining employment, during that time. His eventual need for renal replacement therapy would have seen him start dialysis in a much better physical and psychological condition. 
In contrast, the second patient depicts a more successful early intervention scenario with a significant improvement in quality of life for the patient and reduction in health care costs.

\section{Patient Scenario Two: Early Referral to Nephrology Service}

A 42-year-old woman with the established diagnosis of diabetic nephropathy and hypertension was referred by her primary care physician to the renal clinic at a city hospital 11 years ago for control of her hypertension and ongoing care of her kidney disease. At her initial visit, her blood pressure was 190/100 $\mathrm{mm} \mathrm{Hg}$ and her glomerular filtration rate was $70 \mathrm{ml} / \mathrm{min}$. Treatment with the ACE inhibitor, enalapril, was commenced and the patient was followed up several times a year in the renal and diabetes clinics. Blood sugar was well controlled by strict diet and oral medication. Seven years ago her weight was $76 \mathrm{~kg}$; Blood Urea Nitrogen (BUN) $10 \mathrm{mmol} / \mathrm{l}$ and serum creatinine 135mmol/l. Six years ago the serum calcium was $2.1 \mathrm{mmol} / \mathrm{l}$ and phosphate2.0 $\mathrm{mmol} / \mathrm{l}$. Calcium carbonate therapy was started. Three years ago, the BUN had risen to $30 \mathrm{mmol} / \mathrm{l}$; the serum creatinine to $250 \mathrm{mmol} / \mathrm{l}$ and the serum albumin was $40 \mathrm{~g} / \mathrm{L}$. Four months later, iron supplementation and erythropoietin were started when her haemogloblin was noted to be 98g/l. After a home visit by the pre-dialysis coordinator to discuss treatment options, and several subsequent telephone conversations, the patient chose peritoneal dialysis as her renal replacement therapy. Mild uraemic symptoms appeared four months later. The blood pressure was 130/82 mmHg; GFR $12 \mathrm{ml} / \mathrm{min}$; haemoglobin 121g/l; BUN 35 mmol/l; serum creatinine $350 \mathrm{mmol} / \mathrm{l}$; albumin 38g/l; calcium $2.2 \mathrm{mmol} / \mathrm{l}$ and phosphate1.4mmol/l. A peritoneal dialysis catheter was inserted, and one month later she commenced dialysis in the home training center. One week later she had completed her training and returned home on continuous ambulatory peritoneal dialysis and later received a cadaveric kidney transplant.

Patient scenario two describes a completely different situation, one that demonstrates an ideal process to manage progressive diabetic kidney disease. The primary care physician picked up that she had some kidney damage early and referred her to the nephrology health care team in a timely manner. She was followed regularly and medications were commenced at different times during the progression of the disease to minimise complications. The risk of succumbing to the long-term effects of hypertension, anaemia, and bone disease were significantly reduced. Good dietary advice maintained excellent blood glucose control and prevented malnutrition. 
The progression of the disease for this woman in the second scenario took 11 years to reach end stage kidney failure; this probably delayed the need for renal replacement therapy. The extended period of time before end stage kidney failure occurred allowed her to come to terms with the disease and gave her access to education and support. She was able to make an informed and considered decision about the best treatment option for her and her family. Hospitalisation was minimised and self-care dialysis training kept her independent and functioning in the community. Due to her good physical condition at commencement of dialysis and absence of complications she was entered onto the transplant waiting list and was fortunate enough to have a transplant.

The two case scenarios demonstrate significantly different outcomes for the two patients. The 'control and awareness' aspects of disease management inherent in early intervention can assist in retarding the progression of kidney disease. Not all early intervention recipients will respond in the ideal way, however the literature suggests that even delaying end stage kidney failure by shorter periods, such as $12-24$ months, make a huge difference to patients' quality of life and their treatment outcomes in the later stages of their chronic disease journey.

Scenario two describes an early intervention service that requires teamwork and a collaborative approach to deliver an effective management programme. I believe expert nephrology nurses are well placed to lead an initiative to provide a high quality programme that focuses on improving care for the CKD population. The next section of this paper provides some insight into the possibilities and opportunities for nurses as advanced nurse practitioners in the New Zealand nephrology environment. 


\section{SECTION FOUR: NURSING PRACTICE AND AN EARLY INTERVENTION SERVICE}

In this paper, I have highlighted the physical aspects of the development and progression of chronic kidney disease (CKD). I drew attention to ways in which the progression of the disease can be detected, monitored and managed to provide the best possible outcome for patients and to slow the progress of the disease. I also presented two case scenarios that powerfully depict 'human' costs associated with non-intervention in the early stages of the disease, and gains in quality of life terms for the patient and their families when early intervention manages to catch and slow the disease process to enable some form of control over symptoms and loss of function.

Having studied this material carefully in the process of researching this paper and drawing on my experience in the nephrology health care environment, I hold the view that the development of an early intervention health service is necessary as a way of improving the quality of life, reducing the overall impact of CKD on the New Zealand community and in generating better living for patients and their families. It is possible for early intervention services to be delivered across a range of health providers', for example, general practitioners, outpatient departments and public health organisations. In this section of the paper, while I recognise these as possibilities, I concentrated on the potential development of nurses leading an early intervention service.

I have explored this concept under the following headings; the nephrology health care workforce, a history of the contribution of nephrology nursing, nurse practitioners in New Zealand, models and scopes of practice, early intervention - a new initiative in nursing, nephrology nurse practitioner training, costs of an early intervention service and measuring the effectiveness of an early intervention service. 


\section{The Nephrology Health Care Workforce}

The proliferation of evidence advocating early management of chronic kidney disease has not gone unnoticed by nephrology health care professionals. However, increasing numbers and complexity of patients requiring renal replacement therapy have kept these health care professionals busy over the years. As technology has advanced, better data collection and research have provided the nephrology health care team with predictions for the future. The prospect of chronic kidney disease continuing to increase has brought about more urgent calls to prevent and slow the progression of the disease.

As it becomes increasingly evident that early intervention and regular follow up is the key to optimising patient outcomes, there has been little written about providing sufficient health care personnel to carry out this essential work. Some international literature raise concerns about the lack of training nephrologists, and the inevitable shortage of medical specialists in the future (Bolton, 1998; Osinski, 2004; Pereira, 2000). Headley and Wall (2000) estimated that, in the United States of America, there would need to be a three-fold increase in the current number of trainees (an extra 6,400 nephrologists) by the year 2010 to cater for the increasing number of people with chronic kidney disease. It has been suggested that the use of physician assistants or extenders and primary care physicians to manage patient groups during stages one to three of chronic kidney disease could help rectify the problem (Anderson et al., 1999; Osinski, 2004; Pereira, 2000).

Similarly, in New Zealand, a recent analysis of workforce requirements led to the conclusion that there is already a $25 \%$ shortfall in nephrology specialists in this country (National Renal Advisory Board (NRAB), March 2004, workforce report). The NRAB report stated that there are not enough New Zealand trained nephrologists to fill these positions and insufficient trainees to cater for future demand. The workforce report estimated that a further 29.4 full time equivalent nephrologist positions will need to be filled over the next ten years to cope with the demand. As this is unlikely to happen, there clearly needs to be a change in the way in which patients with kidney disease are managed. 
There is frequent reference in the literature to the importance of collaboration and team work among all nephrology health providers in order to better identify and treat kidney disease (Baker \& Thomas, 2001; Levin, 2001; Levin et al., 1997; St Peter et al., 2003). New ways of delivering high quality care need to be developed that ensure appropriate utilisation of available nephrologists with a strong structure of collaboration with other health care professionals (Parker et al., 2004).

Expanding the role of the advanced nephrology nurse to practice in the area of intervention and early detection may go some way to address the predicted growth in kidney disease and lack of medical personnel. Although nurses practicing at an advanced level are relatively new in New Zealand, they are well established in the United States (U.S.), Canada, and Europe.

In March 2000 there were an estimated 102,829 advanced practice nurses practicing in the U.S. (Ministry of Health, 2002). In the U.S. certified midwives and registered nurse anaesthetists have been practicing for the past 25 years, while the ambulatory care setting in the areas of adult, obstetric and paediatric primary care were developed more recently (Headley \& Wall, 2000). International research has consistently demonstrated that the clinical and financial effectiveness of the advanced nurse practitioner is at least comparable to the medical practitioner doing the same job (Horrock, Anderson, \& Salisbury, 2002; Ministry of Health, 2002).

\section{Nephrology Nursing Contribution - History}

It is acknowledged in the literature that nephrologists have not single handedly managed the chronic and end stage kidney disease population up until now. They have relied heavily on a multidisciplinary approach that spans the spectrum of kidney disease, from diagnosis to, ultimately, death. The input from different health professionals has been essential in providing comprehensive and high quality care for the patient and their families. Nurses have been a major contributor to the nephrology health care team for decades. The need for highly skilled nephrology nurses was recognised in the mid seventies when Shapiro (1976) developed an educational programme for nurses that related to the unique needs of the patient with end stage kidney failure. The nurses who progressed through this programme were subsequently employed in satellite dialysis units under the direct supervision of a nephrologist. 
Shapiro (1976) stated that there was a significant economic benefit in having a nephrologytrained nurse assist in managing 50 chronic dialysis patients rather than utilising the full services of a nephrologist. Traditionally the advancement of renal nursing focussed on managing haemodialysis and peritoneal patients where they were valued for their availability and accountability for dialysis orders, emergency evaluations, and prevention and maintenance skills.

This is reflected in the United Kingdom, Canadian, American and, more recently, Australian experiences (Bolton, 1998; Bonner \& Walker, 2004; Easom, 2000; Headley \& Wall, 2000).

Varying degrees of autonomy in the workplace are reported, including conducting outpatient clinics, writing dialysis orders, implementing standing orders and limited prescribing (Bolton, 1998). The nephrology nurse has undoubtedly been providing advanced practice nursing care to dialysis and transplantation patients for many years.

However, the notion of the advanced practice nephrology nurse being well positioned to extend their practice into early kidney disease management has not been clearly articulated. A nephrology manpower study conducted in the U.S. in 1997 found that $20.7 \%$ of the 428 surveyed nephrologists were working with advanced nephrology nurses or nurse practitioners. Data on these roles was limited but some involvement in preventative care was mentioned (Anderson et al., 1999).

A recent American Chronic Kidney Disease Initiative recommended that 'nurse directed chronic kidney disease care' should be considered as a model to improve patient outcomes (Parker et al., 2004, p. 714). Other literature included the nephrology nurse as part of the team approach to patient management (Levey et al., 2003; Levin, 2001; Levin et al., 1997; Osinski, 2004; Pereira, 2000; St Peter et al., 2003) but did not discuss the potential for the expert nephrology nurse practicing as an independent, early interventionalist. This brings the discussion to consider positioning nephrology nurses in New Zealand in an early intervention service using the nurse practitioner framework that has recently been created by the Nursing Council of New Zealand (2002) and endorsed by the government (Ministry of Health, 2002). 


\section{Nurse Practitioners in New Zealand}

The role of the advanced practice nephrology nurse in New Zealand has not been captured in the literature, although from my experience I believe there are many highly skilled nephrology nurses present in the work force. The report of the Ministerial Taskforce on Nursing (1998) acknowledged the under-utilisation of advanced level nurses and advocated development of the nursing profile in the community.

The Ministry of Health has since endorsed the nurse practitioner (NP) role in New Zealand and clearly supports extending nursing services across all areas of health care (Ministry of Health, 2002). A NP is a clinical expert who works in a specific area of practice incorporating advanced knowledge and skills into their practice (Nursing Council of New Zealand, 2002). The Ministry has provided the District Health Boards with a framework to develop a nurse practitioner workforce that would fit into such services as acute care, primary health settings and secondary settings (Ministry of Health, 2002).

When the 'Nurse Practitioners in New Zealand' document was published in 2002 it stated that a 'large District Health Board (DHB)' (Ministry of Health, 2002, p.41) intended to develop a model for a nurse practitioner that combined a kidney disease management and Maori health role. In this model the nurse practitioner would be based in the renal service, but would work predominantly in the dialysis unit and the community. Patients would access the service through dialysis services, or would be referred by health professionals from the wider nephrology community.

The work proposed for the nurse practitioner working in kidney disease management encompassed assessment, diagnosis, monitoring and treatment of symptoms of the dialysis patients plus prescription and adjustment of medications and treatments on a regular ongoing basis. Ordering of diagnostic tests and monitoring results and referral to other specialist services were also part of the described nurse practitioner model. The NP was also expected to provide education to the patient and whanau in self-care, disease management and preventative aspects of CKD. 
The document (Ministry of Health, 2002) went on to include anticipation and prevention of the progression of kidney disease and its complications and liaison, co-ordination and support of other health care professionals involved with the patient (eg, general practitioner, dialysis and diabetic staff, specialists and the health care team) as part of the day to day work requirements of the NP. Facilitation of the development of nurses and other health care professionals in the care of patients with both diabetes and renal disease concluded the list of services required from a nurse practitioner working in this model.

I believe that the scope of practice proposed in this model is too broad and requires considerable refining to provide a realistic vision of advanced nephrology nursing in New Zealand. For example, the job of assessing, monitoring and treating patients receiving haemodialysis in a large tertiary hospital could easily be a full-time commitment, with patient loads of around 80-100 across community and hospital services. A similar role, focusing on the peritoneal dialysis population, could be effective with particular expertise and knowledge required in peritoneal dialysis therapies. It would be unrealistic to expect one person to have the depth of knowledge and experience to provide quality care across such a wide spectrum of the disease process as proposed in the aforementioned model.

There must be collaboration among senior nephrology nurses in New Zealand to ensure that the nephrology nurse practitioner role is realistically scoped, clinically focussed, and is not seen as exclusively consulting and advising other health care workers. Frances Hughes, Chief Nursing Advisor for the Ministry of Health, described the nurse practitioner role as providing 'the highest level of clinical expertise in nursing' (Ministry of Health, 2002, p. v). It is important that this vision is kept in the forefront as District Health Boards across New Zealand develop these positions. In the context of nephrology nursing, forums to discuss nurse practitioner scopes of practice could take place at Renal Society of Australasia conferences, regular national educator meetings and several other company sponsored workshops and seminars held during the year. The New Zealand Renal Advisory Board, in particular the nurses on the board, have an opportunity to lead developments for nephrology nurse practitioners on a national level and ensure there is consistency and clarity of roles and measurable performance outcomes. 


\section{Models and Scopes of Practice}

The Ministry of Health (2002) has created four generic models of care for the nurse practitioner; these are summarised in Appendix One. Model Four, from these generic models, describes the 'nurse practitioner specialty services as an expert in prevention, management or rehabilitation of particular health issues' (Ministry of Health, 2002, p. 40). This model fits well with the current nephrology nursing work environment and provides an excellent framework to build in the nurse practitioner role.

Nephrology nurses have traditionally been involved in caring for patients with kidney disease at various stages of the chronic illness journey. Over many years these stages have created nursing expertise in the areas of chronic dialysis, kidney transplantation and pre-dialysis management. With proven expertise in these three areas of nephrology nursing, scopes of practice would be relatively easy to develop using the 'nurse practitioner specialty services' generic model from the Ministry of Health (2002, p.40). Broad concepts for a nurse practitioner role in the three areas of established nephrology nursing expertise are discussed below.

\section{Chronic Dialysis Management}

The role of the expert nurse in the care of dialysis patients is already well established and is specific to caring for patients with end stage kidney disease requiring haemodialysis or peritoneal dialysis. A nurse practitioner working within the area of chronic dialysis patient management is likely to be the first nephrology-nursing model of care to emerge in New Zealand because this has been an area where nurses have managed and coordinated patient care for many years. Relationships and trust among the nephrology team have been built up over this time and the nursing staff already carry out the day to day patient management in hospital and community based dialysis units throughout the country. The nurses get to know the dialysis patient and their families intimately over time and regularly deal with the physical, cultural, spiritual, psychosocial and psychological needs of the patient and their families. They have often nursed the patient through many acute illnesses or hospitalisations and have excellent knowledge of the patient's medical and social history. This growing patient group has complex, ongoing health care needs that require regular assessment and treatment modification. The nephrologist often does not have the time required to regularly assess and manage chronic dialysis patients. 
This task is often left to a more junior doctor who might only work in the nephrology service for a short period of time, and may or may not know the patient. It seems logical to develop a scope of practice, in haemo and/or peritoneal dialysis that allows a nurse to provide holistic care, including limited prescribing rights, without direct medical supervision. International experience has shown that the nurse practitioner model in this area of nephrology can provide high quality and cost effective health care (Bolton, 1998; Easom, 2000; Headley \& Wall, 2000).

\section{Kidney Transplantation Management}

The management of patients' pre and post kidney transplantation is another specific field of nursing practice within the spectrum of nephrology health care. Transplant nursing coordinator and specialist roles have been present in nephrology health care for many years. This work has included managing patients pre-transplantation, waiting list maintenance, preparing live kidney donors and the recipients, immediate post-operative care of cadaveric and live transplantation recipients, and ongoing support and management of recipients at home. Patient follow up after a kidney transplant often extends to many years, with the transplant nurse playing a pivotal role in supporting these patients to keep well, and out of hospital. Again, a nurse practitioner role could be created, as there is extensive skill and experience already in place in New Zealand. The nephrology nurse working in this environment has detailed knowledge of the patient and their family, and the complex issues and complications arising from chronic kidney disease and kidney transplantation.

\section{Pre-dialysis Coordination}

The late stages (stages four and five) of chronic kidney disease is an intense time for the patient as they approach end stage kidney failure, with worsening symptoms and the prospect of needing renal replacement therapy to stay alive imminent. Over the past seven years in New Zealand the pre-dialysis nurse coordinator role has developed to meet the needs of this group of patients. The nurse has a central role in providing information and support to the patient and their family about treatment options. They carry out home visit assessments and work closely with the nephrology health care team of doctor, dietitian, social worker and pharmacist to ensure the best outcome for the patient. In addition they liaise with radiological and surgical services for vascular access or peritoneal dialysis catheter placement, and organise dialysis starting dates including commencing the home training programme if appropriate. 
The increase in patient numbers and complexity at this stage of the disease process requires frequent patient assessment and coordination between health care services. A nurse practitioner role (NP) could extend the coordinator role to include nurse led clinics, vascular access management, direct referral to other services and working collaboratively to ensure timely initiation of treatment. Limited prescribing rights would be essential to this role as frequent medication assessment and adjustments are required as the patient nears the end stages of the disease.

The three scopes of practice discussed above are areas of nephrology health care that expert nurses have participated in for many years. My feeling is that nephrology NPs will be practicing within District Health Boards and other health care services in these scopes of practice in the near future. While I encourage and support extending expert nephrology nurses in these areas, I also think that the health care providers need to direct energy and resources into slowing the alarming growth of chronic and end stage kidney disease in this country. Nephrology nurses must take a proactive role in developing a strong argument to create a long-term strategy to prevent the predicted CKD growth and improve the high morbidity and mortality rate in the CKD population. Consequently, I have proposed that the nephrology nurse practitioner could extend their scope of practice into the emerging area of early disease management for patients with chronic kidney disease.

\section{Nurse Practitioner as an Early Interventionalist: A new initiative for nursing}

There is currently no nephrology nursing input during the early stages of chronic kidney disease in New Zealand. Establishing the role of a nurse practitioner as an early interventionalist in an established nephrology health care workforce would be a challenge. However, given government support for advanced nursing practice and nurse practitioner roles, the lack of trainee nephrologists, and the worldwide focus on early detection and management of kidney disease, the rationale for nephrology nurses in early disease management has never been better. In order to gain some insight into the development of a NP role in early disease management I went looking for programmes currently running in New Zealand that involve nurses in the prevention and management of chronic disease. I contacted and spoke with a cardiac nurse consultant who coordinates a chronic cardiac disease programme in a large teaching hospital (Judy Dewar, cardiac nurse consultant, personal communication, May 2004). 
This cardiac disease management programme employs an expert cardiac nurse who runs an outpatient clinic independent of medical staff and manages a patient caseload within the community. The programme provides ongoing education, advice and support for complex cardiac patients and their families. The primary goals of the programme are to maintain the patient with chronic cardiac failure in the community, reduce hospital admissions, ensure patients are in optimal condition prior to and post cardiac surgery and promote cardiac health care in the community and primary health care sector (Hutt Valley Health Job Description, 2000). While the nurse currently working in this position does not have prescribing rights and is not a nurse practitioner, the opportunity of progression to this level is possible in the future.

The research I have done for this paper including my exposure to the cardiac disease management programme, provided me with the resources to develop a model for an early intervention service for the chronic kidney disease population. The model I have created is outlined in Figure Four. This model describes how a nephrology nurse practitioner could participate in a multidisciplinary approach to slow the progression of kidney disease and maintain optimal health prior to and post initiation of renal replacement therapy. It requires collaboration and support from, most importantly, the nephrology health care team but also health care providers such as the district health board, primary health care organisations and Maori and Pacific Island health providers.

The early intervention service described in Figure Four begins with the identification of those individuals considered to be at high risk of suffering from kidney disease. Screening of 'at risk' populations could be undertaken by a number of health care professionals in the community using simple, well-established biochemical tests, for example, glomerular filtration rate and proteinuria measurement. If the test results indicate possible kidney dysfunction, a referral to a nephrologist is necessary to obtain an accurate diagnosis and create a long-term patient management plan. The nephrologist would ideally see patients at the very early stages of the disease process (Stages One and Two CKD), set up individual management plans, and refer them on to the nephrology NP. Ideally, national guidelines targeting specific aspects of CKD management would be available to assist the nephrologist and NP to provide the best possible outcome for the patient. The NP would be responsible for the implementation of a plan of care designed specifically for a patient, and would work in collaboration with the multidisciplinary team. The NP would review the patient on a regular long-term basis and consult with the nephrologist as issues arise outside of his or her scope of practice. 


\section{Identify High Risk Population}

- Over 50 years old

- Hypertensive

- Diabetic

- Family history of kidney disease

- Smoker

- Maori or Pacific Island heritage

Screen for Kidney Disease

WHO

- Primary Health Organisation

- General Practitioner

- Public Health Nurse

- $\quad$ Practice Nurse

- Cardiologist

- Diabetologist

- Pharmacist
HOW
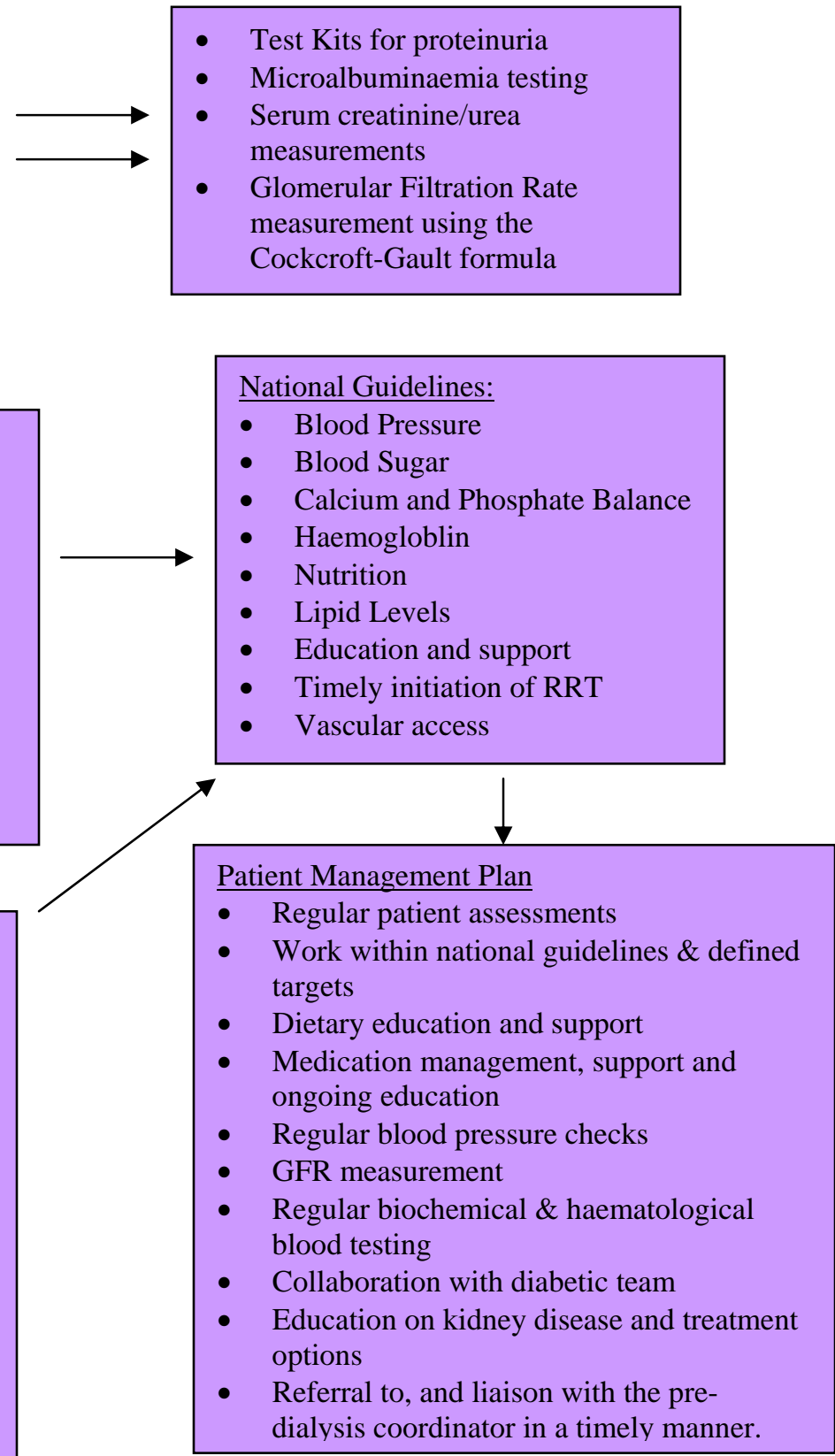

Test Kits for proteinuria

Microalbuminaemia testing measurements measurement using the Cockcroft-Gault formula

National Guidelines:

Calcium and Phosphate Balance

- Education and support

- Timely initiation of RRT

Vascular access

Patient Management Plan

Regular patient assessments Work within

Medication management, support and

Regular biochemical \& haematologica blood testing

- Collaboration with diabetic team

Education on kidney disease and treatmen Referral to, and liaison with the predialysis coordinator in a timely manner.

\section{Nephrologist Consultation}

- $\quad$ Early referral (stage 1-3)

- Develop national guidelines for managing early kidney disease

- Diagnostic testing eg. kidney biopsy

- $\quad$ Provides support and advice to other health care practitioners ie. seminars, workshop sessions

- $\quad$ Oversee patient management plan

- $\quad$ Referral to, and collaboration with nephrology nurse practitioner

\begin{tabular}{|l|}
\hline \multicolumn{1}{|l}{ Nephrology Nurse Practitioner } \\
Implements patient management plan \\
Works with: \\
- $\quad$ Nephrologist \\
- $\quad$ providers \\
- $\quad$ Primary health care Organisation \\
- $\quad$ Practice Nurse \\
- $\quad$ Piabetic Nurse \\
- $\quad$ Dietitian \\
- $\quad$ Palliative care team when \\
$\quad$ appropriate \\
\hline
\end{tabular}

Figure 4: An Early Intervention Service for Chronic Kidney Disease 
In the proposed early intervention service as described in Figure Four, the NP would be employed by a District Health Board or other health service provider and work across inpatient and community settings. Access to the NP would be through referral from the nephrologist initially, although direct referral from other sources such as primary health care organisations, general practitioners or the diabetic management team may be possible once the role is established and processes are in place.

Primary responsibilities of the NP would be regular patient assessment and follow up in an outpatient clinic, biochemical and haematological measurement, medication adjustment, education, support, and referral to other health care professionals. I have detailed my vision of the responsibilities and requirements of a nurse practitioner working in early intervention kidney disease in a job description format in Appendix Three. The job description I have created has the essential elements necessary for a nurse practitioner role, however, a detailed structure would need to be constructed at a local level to meet the needs of the patient population within a particular geographical location and the District Health Board's strategic plan. Ongoing development of the role would be essential and would require flexibility and open communication between the local nephrology community and the health care provider management team. The qualifications and training for a NP working in nephrology health care needs careful consideration in light of national certification requirements and the needs of the local population.

\section{Nephrology Nurse Practitioner Training Requirement}

The literature provided minimal information about appropriate training for advanced practice nurses or NPs in the nephrology setting. Bolton (1998) did assist in this matter with a discussion about the experiences of the University of Virginia Nephrology Division and Kidney Center where nephrology NPs have been employed as an integral part of a collaborative care model in managing patients receiving dialysis therapy since 1973. It was useful to look at how this model had developed over the years. The NPs described in the model had extensive clinical nursing experience and were graduates of a 12-month, certified NP program. In addition, many had Masters in Nursing qualifications. 
Training also consisted of six to 12 months of on-the-job clinical work supervised by a nephrologist. Attendance and participation in nephrology conferences and regular medical education meetings was mandatory. The directors of the dialysis units and division managers provided supervision and written evaluation of performance. These nurses were responsible for a caseload of 80-100 dialysis patients. Their primary role was assessment and preventative intervention of patient receiving dialysis therapy with limited prescribing rights. This model emphasised the importance of collaboration among all team members including the nephrologist, nurse practitioner, dialysis staff, dietitian, social worker, vascular access surgeon and various consultants. After more than 30 years experience and refinement the NP role was seen as 'a pivotal component of the patient care model' in the institution (Bolton, 1998, p. 793). Although the American model of care focuses on the NP managing patients on dialysis therapy, it provides a useful guide when considering the most appropriate training and ongoing education of NPs in the pre-dialysis stage of CKD.

In New Zealand, the NP title can only be used if the nurse has been registered with the Nursing Council of New Zealand (Ministry of Health, 2002). A person aspiring to NP status in New Zealand must comply with the Nursing Council of New Zealand's registration criteria that includes a clinically focused master's degree or equivalent and four to five years' experience in the relevant scope of practice. The applicant must also meet the Nursing Council competencies for NPs (Appendix Two) and undergo a panel assessment (Ministry of Health, 2002). In addition, a NP can become a registered nurse prescriber if they successfully complete a Nursing Council approved, masters level pharmacology course and meet an extra Nursing Council competency. Although the Medicines Act 1981 was amended in 1999 to allow nurses to prescribe a specified list of medicines (Ministry of Health, 2002), issues are still being addressed to allow nurse prescribing to progress.

Although the Nursing Council of New Zealand allows NPs to choose if they wish to prescribe medicines or not in their scope of practice, it would be necessary in an early kidney disease intervention service to obtain prescribing rights. When considering the key responsibilities in the day to day work of health care professionals in early kidney disease management, as described in the literature, monitoring and adjusting medications (eg. antihypertensives, erthropoieitin, phosphate binders, vitamin D supplements \& lipid lowering drugs) are a significant part of the workload. 
Therefore, a nephrology NP would need to be able to modify medication doses (within a predetermined scope of practice) without direct medical supervision to be effective in their role. The need for on-the-job training for six to 12 months has been shown to be an important part of the training process (Bolton, 1998). I believe that this would be a valuable time to build relationships and trust within the nephrology team, and clarify new roles and responsibilities.

In summary, the NP working in early disease management would need to be registered as a NP with the Nursing Council of New Zealand, be certified to prescribe a specified list of medicines and be supported in an on-the-job training programme for six to twelve months to optimise their effectiveness. The extra costs involved in training and sustaining nurses at a higher level must be justifiable. The cost of the NP service in early intervention is discussed in the next section as part of a broader discussion of the potential cost savings if renal replacement therapy could be delayed and patients are provided with optimal treatment throughout their chronic kidney disease journey.

\section{Costs of an Early Intervention Service}

Renal replacement therapy is expensive and incurs an enormous burden on the national health care budget (Collins, 1998). I searched the literature to ascertain the cost implications of CKD in New Zealand and found very little information. One article estimated that dialysis in New Zealand cost 'from $\$ 25,000$ to $\$ 55,000$ per patient per year depending upon the modality of therapy employed' that is, haemodialysis or peritoneal dialysis (Collins, 1998, p. 13). These figures are now six years old and are likely to be inaccurate.

With a lack of national information available on this subject, I looked internationally for assistance. The United States Renal Data System (USRDS) collects and analyses data on costs associated with chronic kidney disease (St Peter et al., 2003). Using forecasting and time series analysis the USRDS predicts that the costs associated with CKD will escalate from $\$ 11.8$ billion US to more than $\$ 28.3$ billion US by 2010. A Canadian study calculated haemodialysis costs at around $\$ 55,000$ to $\$ 66,000$ (Canadian Dollars) per patient per annum (McFarlane et al., 2003). Another Canadian group (Goeree et al., 1995) published their 1993 cost analysis of dialysis showing costs at $\$ 54,929$ for hospital haemodialysis, $\$ 43,313$ for self-care haemodialysis, \$31,918 for peritoneal dialysis and \$26,048 for home haemodialysis. 
In 2001, Dr Adeera Levin estimated dialysis treatment to cost $\$ 45,000$ US per year per person (Levin, 2001). It is clear from the international figures that the cost of treating the CKD population uses up a significant amount of any health care budget and the predictions of increases are of major concern worldwide. Without solid data on costs for dialysis and transplantation in New Zealand, I sought the advice and assistance of the financial manager of Medical and Surgical Services, Michael Bishop, at my District Health Board (DHB). The task of accurately measuring the cost of renal replacement therapy and treating the CKD population is complex and beyond the scope of this paper. However, for the purposes of demonstrating the savings that could potentially be made by delaying renal replacement therapy, the basic costs for dialysis therapy and transplantation were calculated at a local DHB level. These costs appear to be less than those stated in the international literature, this might be because only the basic costs of dialysis were included. Associated costs of dialysis such as medications, vascular access and clinic visits were not included, as they do not count as savings in the long term. Nurse's and other health care worker's salaries are also higher in the US and Canada that may also explain the cost differences.

Currently, in New Zealand it is estimated to cost an average of around \$35,000 per annum per person for maintenance haemodialysis or peritoneal dialysis (Michael Bishop, personal communication, August 2004). This means that the 1600 people receiving dialysis therapy in New Zealand draws \$56 million per year from the health care budget, with these costs predicted to rise each year. In contrast, patients who have received a kidney transplant require $\$ 10,000$ each per annum, excluding the actual surgical procedure that is priced at $\$ 35,000$, for the necessary medications and ongoing nephrology service support. Therefore, the 1114 kidney transplant recipients in the community (ANZData Registry, 2003) cost more than $\$ 11$ million per annum to sustain, this makes kidney transplantation the most cost effective treatment for end stage kidney failure. If the total cost of providing renal replacement therapy (dialysis and transplantation) for patients who have reached end stage kidney failure is added together from the calculations above, including the $\$ 4$ million a year required for transplant surgery, it comes to over $\$ 70$ million per year.

The predicted increase in demand for renal replacement therapy in the next ten years will result in an even greater demand for the health care dollar. Funds available in the future may be inadequate to provide a high quality nephrology service and rationing dialysis treatment may be necessary. Nephrology health care professionals have the opportunity to plan ahead and focus on relieving the cost burden. 
Using the calculated cost of dialysis at $\$ 35,000$ per annum, it could be possible to achieve significant savings by delaying the onset of end stage kidney failure, even if the delay was only a few months. For example, if 50 individuals were kept off dialysis therapy for only three-months as a result of receiving treatment early in the disease process, a cost saving of $\$ 437,000$ would be attained. However, there is encouraging evidence that suggests longer delays could be obtained if an effective early intervention service was in place. If larger patient numbers were included in an early intervention service, and dialysis could be delayed for a year or more, millions of dollars could be saved. The potential savings achieved by providing an early intervention service are demonstrated in Table Five where a conservative figure of $\$ 6.8$ million is shown as savings incurred if 100 patients were kept off dialysis therapy for two years.

In addition, the savings associated with an early intervention service in terms of reduced acute admissions to hospital and decreased long term complications such as heart disease, bone disease, malnutrition and peripheral vascular disease, could amount to many more millions of dollars. The literature did not show clearly demonstrated savings in this area. However, many studies that looked at optimising care in CKD acknowledged that the financial benefits of reducing associated CKD complications could be significant (Cass et al., 2002; Levin, 2001; National Kidney Foundation; 2002; Nissenson, 2003; St Peter et al., 2003; Silverberg, 2003).

Table 5: Delayed Dialysis Cost Savings

\begin{tabular}{|l|l|l|l|l|}
\hline $\begin{array}{l}\text { Patient } \\
\text { Numbers }\end{array}$ & $\mathbf{3}$ Month Delay & $\mathbf{6}$ Month Delay & $\mathbf{1}$ Year Delay & 2 year Delay \\
\hline $\mathbf{1 0}$ & $\$ 87,500$ & $\$ 175,000$ & $\$ 350,000$ & $\$ 700,000$ \\
\hline $\mathbf{2 0}$ & $\$ 175,000$ & $\$ 350,000$ & $\$ 700,000$ & $\$ 1.4$ Million \\
\hline $\mathbf{5 0}$ & $\$ 437,000$ & $\$ 874,000$ & $\$ 1.7$ Million & $\$ 3.4$ Million \\
\hline $\mathbf{8 0}$ & $\$ 700,000$ & $\$ 1.4$ Million & $\$ 2.8$ Million & $\$ 5.6$ Million \\
\hline $\mathbf{1 0 0}$ & $\$ 874,000$ & $\$ 1.7$ Million & $\$ 3.4$ Million & $\$ 6.8$ Million \\
\hline
\end{tabular}

The potential to save many millions of dollars as demonstrated in Table Five provides a convincing argument for the development of an early intervention service. 
The costs of employing a NP to lead an early intervention service would easily be accommodated if the savings demonstrated were realised. The New Zealand Nurses Organisation (2003) recommends that a NP should be paid between $\$ 70,000$ and $\$ 100,000$ per annum. The additional costs of a mobile phone, car, administrative support and office would also need to be included in the employment package and negotiated at a local level.

If the NP has a patient load of 100 patients and dialysis is delayed by even a short period, for example, three months, it would clearly be a worthwhile and cost effective initiative. Again, the literature suggests that there are likely to be additional savings in the reduction of long term complications and acute admissions to hospital if patients are treated in the early stages of the disease process. Other cost benefits that were discussed in the literature, as a result of early intervention programmes, were an increase in patients choosing to do the cheaper, home based dialysis therapies and patients maintaining employment for longer (Baker \& Thomas, 2001; Compton, Provenzano \& Curtis, 2002).

\section{Measuring the Effectiveness of an Early Intervention Service}

There appears to be a strong case for the implementation of an early intervention service in CKD and over time, I believe that if it was developed the collection of appropriate data would confirm the effectiveness of such a service. The overall effectiveness of an early intervention service would need to be measured against patient outcomes such as the number of acute admissions, late referrals and emergency dialysis treatments, temporary vascular access placement, functioning arteriovenous fistula and patient referrals to the nephrology health care team in the early stages of CKD.

Measuring blood pressure and blood sugar control, nutritional status, glomerular filtration rate, haemoglobin levels, blood lipid levels and calcium and phosphate levels would also show if the service were reaching targets recommended in the literature for optimal health. The human costs could also be assessed through quality of life and patient satisfaction surveys and looking at the number of patients who remain in the workforce as their disease progresses. The CKD populations differ from region to region in New Zealand, it would therefore be up to each District Health Board to determine realistic outcomes based on their patient population (St Peter et al., 2003). 
In summary, there seems to be little doubt that the current nephrology health care workforce structures that support patients with CKD will not be sustainable in the future. In addition, the benefits of intervening in the disease at an early stage are becoming increasingly evident. Both of these factors lead to the conclusion that there is an immediate need for an increase in nephrology health care professionals working in New Zealand. I believe that the extension of the expert nephrology nurse into the NP role could contribute to reducing the workforce shortages and maintain a high quality, cost effective service.

Expert nephrology nurses have been working as NPs overseas for many years, playing a major role in the management of patients receiving dialysis therapy. The NP has been shown to provide a high quality and economically beneficial service to end stage kidney failure patients. The introduction of the NP in New Zealand in 2002 has provided the opportunity for nephrology nurses to develop scopes of practice that fit within the Nursing Council of New Zealand NP framework. The areas of chronic dialysis, transplantation and pre-dialysis could easily accommodate a NP scope of practice, as they already have a strong nursing presence.

The creation of a NP position as an early kidney disease interventionalist would be a great challenge as it is a relatively new area of health care and one that nurses in New Zealand have not encountered before. I found limited literature on nurses working in early disease management, which led me to seek assistance from my local area. Consequently, I was able to utilise the information gained from the chronic cardiac management programme in conjunction with other research I have done to develop a model depicting an intervention service for the CKD population. In particular I have focussed on the participation of the NP in this model, as I believe they are pivotal to the successful implementation of such a service.

The training requirements for the nephrology NP role were discussed and a job description for the NP working in early kidney disease management was developed to provide a realistic example of the day to day workload and scope of practice that could be expected of a nurse working at that level. In order to demonstrate the cost effectiveness of an early intervention service I sought local assistance to broadly cost haemodialysis, peritoneal dialysis and transplantation treatments. I applied these costs to calculate the potential savings that could be gained if renal replacement therapy was delayed. The results showed that there was enormous potential for significant cost benefits if dialysis was delayed for even a short period. 
In addition, the literature suggests that an early intervention service could reduce complications associated with CKD that may also save many millions of dollars and improve the quality of life for the patient and their families. Employing a NP to lead an early intervention service was clearly shown to be worth doing from a financial perspective. Measuring the effectiveness of an early intervention service including the performance of a NP as part of that service would be a requirement from any health care provider funding such a scheme. Over time, an early intervention service would need to show evidence that the CKD patient and their families are benefiting from a cost effective and high quality service. 


\section{CONCLUSION}

The number of people suffering from chronic kidney disease and end stage kidney failure is on the rise throughout the world. The reason for this is primarily due to diabetic nephropathy, a complication of diabetes mellitus. This disease is keenly felt in New Zealand where diabetic nephropathy is currently responsible for almost half of all new kidney failure patients requiring renal replacement therapy.

There are predictions that the number of people with end-stage kidney failure will double in the next ten years, placing unprecedented stress on health care resources. As a consequence of this rapid growth there has been a change in emphasis in the practice of nephrology health care at an international level. In the past, most of the health care energy and resources was focussed on managing end-stage kidney failure that is, haemodialysis, peritoneal dialysis and transplantation therapies. There now appears to be more urgency in the literature around early detection, slowing and prevention of chronic kidney disease and its associated complications.

Researchers have identified the need to classify chronic kidney disease to provide a common language and a framework for clinical practice guidelines, performance measures and quality improvements. The American National Kidney Foundation has developed a five-stage classification system that could provide such a framework. It will be interesting to see if this initiative will be used internationally as a tool to manage chronic kidney disease in the future.

Kidney disease is often difficult to combat due to its insidious nature and lack of early clinical signs and symptoms. The screening of high-risk groups in some countries has become a crucial part of early detection and treatment programmes aimed at slowing disease progression and improving patient outcomes. Unfortunately, the New Zealand Ministry of Health has not yet taken up the challenge of screening and treating these high-risk groups despite available data that can identify them in the New Zealand community. Of particular concern is the high rate of kidney disease in the Maori and Pacific Island population that is only acknowledged in association with diabetes and is not addressed as a separate problem. 
It has been shown in many studies that early management of chronic kidney disease can slow the progression of the disease and significantly improve patient morbidity and mortality. There is strong consensus that conditions such as hypertension, diabetes, anaemia, cardiovascular disease, hyperlipidaemia and bone disease should be aggressively treated in order to improve short and long term patient outcomes. There is also agreement that chronic kidney disease is best approached using a multidisciplinary team and should include ongoing support and education for the patient and their family.

The changes needed to manage chronic kidney disease in the future require a shift in the roles and functions of health care professionals due to the lack of nephrologists and the increase in advanced nursing knowledge and practice. In recent years, the acknowledgment of academic achievement and clinical expertise of New Zealand nurses has brought about government endorsement of the nurse practitioner role. It is appropriate and timely to consider how the nurse practitioner position could benefit patients suffering from chronic kidney disease.

Nurses have played a significant role in the management of end stage kidney disease for many years in the areas of dialysis, transplantation and pre-dialysis coordination. The international literature describes advanced nephrology nursing practice as well-established and highly regarded in these areas. With the benefit of international experience to draw from, the development of similar advanced nursing positions in the New Zealand health care environment would be possible using the Nursing Council of New Zealand framework. The nurse practitioner role in early disease management would be a new and challenging area for nephrology nursing, one that has not previously been seen in this country. The evidence to support early intervention and the endorsement of advanced nursing practice provides a sound argument for developing nurse practitioner positions in early kidney disease management.

The potential for significant financial benefits are demonstrated in an early kidney disease intervention service The cost of employing a nurse practitioner to manage a patient caseload would be worthwhile even if dialysis treatment was delayed by only a few months. There is enormous potential to prevent high health care costs if the delayed treatment time was extended to several years. In addition, the patient benefits in terms of quality of life would be immense. 
As the benefits of early kidney disease management becomes a focus in the health care environment, it is important that nurses show leadership in the development of nursing roles in this area. The nurse practitioner role must maintain a clinical focus with a workload that reflects this. The model of care I proposed would see nurses make a valuable contribution to the health care of the chronic kidney disease population. The key to the success of implementing nephrology nurse practitioner positions in New Zealand is collaborative practice that fully recognises and respects the skills and knowledge that each health care professional brings to the specialty.

In the future, prevention will play an increasingly important part in the daily workload of the nephrology health care professional. In the short term things will get busier; in the longer term, if preventative strategies work, there should be a reduction in new cases of end stage kidney failure and the number of New Zealanders who are committed to a life on dialysis. 


\section{APPENDICES}

\section{APPENDIX ONE}

\section{Ministry of Health: Nurse Practitioner Generic Models of Care}

This is a summary of the four generic models of care for nurse practitioners proposed by the (Ministry of Health, 2002, p.11).

\section{Model 1: Integrated nursing teams}

A team of nurses and nurse practitioners provides, co-ordinates and manages health promotion and disease prevention across the continuum of care. For example, integrated primary health care nursing teams working out of primary organisations and providing risk assessment, first contact care, case management of clients with chronic conditions, and services for whanau, hapu, iwi and Maori communities.

\section{Model 2: Nurse consultancy}

The nurse practitioner works independently and refers clients to other health professionals, where required. Collaborative practice arrangements and care decisions may also dominate. For example, within hospital settings, between primary and secondary, and secondary and tertiary, health care services, or between non-government organisations. Provides leadership to nurses and referral to other disciplines.

\section{Model 3: Independent practice}

Nurse practitioners are self-employed and establish their own independent practices offering care and services direct to the public. For example, nurse practitioners contract themselves to provide services to other agencies, hospitals, primary health organisations, non-government organisations, direct to clients.

\section{Model 4: Nurse practitioner specialty services/clinics}

The nurse practitioner is the recognised lead health professional within the health care team for establishing and managing specialty clinics/services for a particular health specialty and/or population group, for example, pain management, anaesthetics, wound management, rehabilitation, disease management. 


\section{APPENDIX TWO}

\section{Nursing Council of New Zealand Competencies for the Nurse Practitioner}

The Nursing Council has developed six generic competencies required by registered nurses applying to the council for approval as nurse practitioners with prescribing rights (Nursing Council of New Zealand, 2001). They are outlined below:

1) Articulates scope of nursing practice and its advancement

2) Show expert practice working collaboratively across settings and within interdisciplinary environments

3) Show effective nursing leadership and consultancy

4) Develops and influences health/socioeconomic policies and nursing practice at a local and national level

5) Shows scholarly research inquiry into nursing practice

6) Prescribes interventions, appliances, treatments and authorised medicines within the scope of practice 


\section{APPENDIX THREE:}

\section{Job Description Example}

$\begin{array}{ll}\text { Position Title: } & \text { Nephrology Nurse Practitioner } \\ & \text { Chronic Kidney Disease Management }\end{array}$

Reports To: $\quad$ Director of Nursing

Medical Nurse Advisor

First Line Manager: Medical Services Manager

$\begin{array}{ll}\text { Functional } & \text { Nephrologists } \\ \text { Relationships: } & \text { General Practitioners } \\ & \text { Practice Nurses } \\ & \text { Diabetic Nurses } \\ & \text { Nephrology/Dialysis Team Leaders } \\ & \text { Pre-Dialysis Nurse Coordinators } \\ & \text { Nephrology clinical nurse specialist } \\ & \text { Nephrology department secretaries/clerks } \\ & \text { Nephrology nursing staff } \\ & \text { Pharmacist, Dietician, Radiology staff } \\ & \text { Primary Health Organisations } \\ & \text { Maori and Pacific Island Health Care Providers } \\ & \text { Training Medical Staff working in nephrology }\end{array}$

\section{Population Base Covered by Position}

The pre end stage kidney disease population for the lower half of the North Island, and Nelson and Blenheim in the South Island. The total population in this area is around 900,000. A caseload of 80-100 patients, 3-4 monthly clinic visits per person per annum or as required. 


\section{Purpose}

- To ensure the timely intervention for patients with early kidney disease in collaboration with the multidisciplinary team.

- To optimise care of patients with pre end stage kidney disease using best practice.

- To promote excellence in nephrology nursing across the continuum of care.

- To provide expert nursing care to patients with pre end stage chronic kidney disease.

- To promote early detection of chronic kidney disease.

- To slow the progression of chronic kidney disease and associated comorbidities.

- To ensure the patient is in optimal condition prior to end stage kidney failure at initiation of renal replacement therapy.

- To ensure the patient experiences a smooth transition between health care services during the progression of their chronic kidney disease.

- To participate in research and translate research findings into clinical practice.

\section{Key Responsibilities}

- Run a nurse-led outpatient clinic for patients diagnosed with early stages of chronic kidney disease.

- Work with the pre-dialysis coordinators and other multidisciplinary team members to ensure timely initiation of renal replacement therapy.

- Work with health care providers in the community, in particular Maori and Pacific Island health providers, diabetic nurses, general practitioners and primary health care organisations to promote early referral and management of chronic kidney disease.

- Manages a patient caseload to implement individual patient management plans set out by the multidisciplinary team.

- Evaluate service by measuring relevant patient outcomes and performance criteria eg. outpatient clinic appointments, patient satisfaction, late/early start renal replacement therapy numbers, prescriptions written, diagnostic tests ordered, vascular access outcomes, anaemia management outcomes. 


\section{Scope of Practice}

- Management of patients diagnosed, by a nephrologist, with chronic kidney disease before requiring renal replacement therapy.

- Practice within specific guidelines set out by the nephrology department and endorsed by the DHB.

- Prescribe medications as specified in the guidelines set out by the nephrology department and endorsed by the DHB and Nursing Council under the Medicine Act 1999.

\section{Qualifications Required}

- New Zealand Nursing Council Nurse Practitioner ${ }^{\mathrm{TM}}$ registration.

- Current New Zealand registered nurse practicing certificate.

- Minimum of 5 years experience in nephrology nursing.

- Working in the New Zealand nephrology health care environment. 


\section{REFERENCES}

Anderson, J., Torres, J., Bitter, D., Anderson, S. \& Briefel, G. (1999). Role of physician assistants in dialysis units and nephrology. American Journal of Kidney Diseases, 33 (4), $647-651$.

Australia and New Zealand Dialysis and Transplant Registry (2003). ANZData Report 2003, Adelaide, South Australia.

Baker, J. \& Thomas, A. (2001). Progressive renal insufficiency program planning: a technique for evaluation and improvement. Nephrology Nursing Journal, 28 (1), 13-18.

Binik, V., Devins, G., Barre, P., Guttman, R., Hollomby, D., Mandin, H., Pual, L., Hons, R. \& Burgess, E. (1993). Live and learn: patient education delays the need to initiate renal replacement therapy in end-stage renal disease. The Journal of Nervous and Mental Disease, 181 (6), 371 - 376.

Bolton, W.K. (1998). Nephrology nurse practitioners in a collaborative care model. American Journal of Kidney Disease, 31 (5), 786 - 793.

Bonner, A. \& Walker, K. (2004). Nephrology nursing: blurring the boundaries: the reality of expert practice. Journal of Clinical Nursing, 13, 210 - 218.

Caring for Australians with Renal Impairment (CARI) Guidelines. Retrieved from the World Wide Web, 12 April 2004, http://www.kidney.org.au

Cass, A., Cunningham, J. Arnold, P., Snelling, P., Wang, Z. \& Hoy, W. (2002). Delayed referral to a nephrologist: outcomes among patients who survive at least one year on dialysis. Medical Journal of Australia, 177, 135 - 138.

Challinor, P. \& Sedgewick, J. (1998). Principles and practice of renal nursing. Cheltenham, United Kingdom, Stanley Thornes (Publishers) Ltd.

Chmielewski, C., Holechek, M., McWilliams, D., Powers, K. \& Tu, A. (1996). Advanced practice in nephrology nursing. Dialysis and Transplantation, 25 (5), 260 - 267.

Churchill, D., Blake, G., Jindal, K., Toffelmire, E. \& Goldstein, M. (1999). Guidelines for treating patients with chronic renal failure. Journal of the American Society of Nephrology, 10, S287 - S321.

Collins, J. (1998). Who should receive dialysis? New Ethicals Journal, 13-18.

Compton, A., Provenzano, R. \& Johnson, A. (2002). The nephrology nurse's role in improved care of patients with chronic kidney disease. Nephrology Nursing Journal, 29 (4), 331 $-336$.

Easom, A.K. (2000). Nephrology APNs: who are we and what do we do? Survey results October 1999. Nephrology Nursing Journal, 27, 187 - 191.

Goeree, R., Manalich, J., Grootendorst, P., Beecroft, M. \& Churchill, D. (1995). Cost analysis of dialysis treatments for end-stage renal disease (ESRD). Clinical Investigation Medicine, 18 (6), 455 - 464.

Harris, D. \& Chaboyer, W. (2002). The expanded role of the critical care nurse: a review of the current position. Australian Critical Care, 15 (4), 133 - 137.

Headley, C.M. \& Wall, B. (2000). Advanced practice nurses: Roles in the hemodialysis unit. Nephrology Nursing Journal, 27 (2), 177 - 186.

Health Funding Authority. (2000). Diabetes 2000, Wellington: Health Funding Authority.

Holland, D. \& Lam, M. (2000). Predictors of early vs. late referral among a retrospective cohort of pre-dialysis patients. Dialysis and Transplantation, 29 (9), 526 -529 \& 533, 534.

Horrock, S., Anderson, E. \& Salisbury, E. (2002). Systematic review of whether nurse practitioners working in primary care can provide equivalent care to doctors. British Medical Journal, 324, 819-23.

King, A. (2004). Government backs comprehensive approach to organ donations. Retrieved from the World Wide Web, 12 April 2004:

http://www.beehive.govt.nz/PrintDocument.cfm?DocumentID=19021 
Knight, J.F. (2002). An introduction to the kidneycheck australia taskforce. Nephrology, 7, S33S35.

Levey, A.S., Coresh, J., Balk, E. \& Kausz, A.T. (2003). National kidney foundation practice guidelines for chronic kidney disease: evaluation, classification, and stratification. Annals of Internal Medicine, 139 (2), 137 - 149.

Levin, A. (2001). What is the "payback" for early intervention in CRI? Nephrology News \& Issues, $17-22$.

Levin, A., Lewis, M., Mortiboy, Faber, S., Hare, I., Porter, E. \& Mendelssohn, D. (1997). Multidisciplinary predialysis programs: quantification and limitations of their impact on patient outcomes in two Canadian settings. American Journal of Kidney Diseases, 29 (4), $533-540$.

Locatelli, F., Vecchio, L.D. \& Manzoni, C. (1998). Morbidity and mortality on maintenance haemodialysis. Nephron, 80 (4), 80 - 102.

MacDougall, L.C. (1998). Quality of life and anaemia: The nephrology experience. Seminars in Oncology, 25 (Suppl. 7), 39 - 42.

McDonald, S., Russ, G., Kerr, P. \& Collins, J. (2002). ESRD in Australia and New Zealand at the end of the millennium: A report from the ANZDATA registry. American Journal of Kidney Disease, 40 (6), 1122 - 1131.

McFarlane, P., Bayoumi, A., Pierratos, A. \& Redelmeier.D.A. (2003). The quality of life and cost utility of home nocturnal and conventional in-center hemodialysis. Kidney International, 64, $1004-1011$.

Mendelsshon, D., Barrett, B., Brownscombe, L., Ethier, J., Greenberg, D., Levin, A. \& Toffelmire, E. (1999). Elevated levels of serum creatinine recommendations for management and referral. Canadian Medical Association Journal, 161 (4), 413 - 424.

Ministerial Taskforce on Nursing. (1998). Report of the Ministerial Taskforce on Nursing: Releasing the potential of nursing. Wellington: Ministry of Health.

Ministry of Health. (2000). The New Zealand Health Strategy. Wellington: Ministry of Health.

Ministry of Health. (2002). Nurse practitioners in New Zealand. Wellington, Ministry of Health.

Morton, R. \& Wooltorton. (2002). Nephrology in practice: a new series. Canadian Medical Association Journal, 166 (2), 195 - 198.

National Kidney Foundation - NKF/DOQI ${ }^{\mathrm{TM}}$. (2002). Clinical practice guidelines for chronic kidney disease. American Journal of Kidney Disease. 36 (supplement 1), S1 - S266.

New Zealand Kidney Foundation. (2004). New Zealand Kidney Foundation Website. Retrieved from the World Wide Web, 6 May 2004: www.nzkidneyfoundation.co.nz

New Zealand Nurses Organisation. (2003). NZNO Position Statement. Nurse Practitioner in New Zealand. Retrieved from the World Wide Web, 26 May 2004: www.nzno.org.nz

Nursing Council of New Zealand. (2001). Framework for post-registration nursing practice education, Wellington, Nursing Council of New Zealand.

Nursing Council of New Zealand. (2002). The nurse practitioner endorsement: guidelines for applicants, Wellington, Nursing Council of New Zealand.

Nissenson, A.R. (2003). Disease management improves outcomes in patients with chronic kidney disease. Nephrology News and Issues, 15,16 \& 18,19.

Obrador, G.T. \& Pereira, B.J.G. (1998). Early referral to the nephrologist and timely initiation of renal replacement therapy: A paradigm shift in the management of patients with chronic renal failure. American Journal of Kidney Disease, 31, 398 - 417.

Orth, S., Stockmann, A., Conradt, C., Ritz, E., Ferro, M \& Kreusser, W. (1998). Smoking as a risk factor for end stage renal failure in men with primary renal disease. Kidney International, 54, 926 - 931.

Osinski, M. (2004). If there is a nephrologist shortage, where are the jobs? Nephrology News and Issues, 18 (4), 33-35.

Parker, J. (1998). Contemporary Nephrology Nursing. New Jersey: American Nephrology Nurses' Association. 
Parker, T., Blantz, R., Hostetter, T., Himmelfarb, J., Kliger, A., Lazarus, M. Nissenson, A., et al., (2004). The chronic kidney disease initiative. Journal of the American Society of Nephrology, 15, 708 - 716.

Parmar, M. (2002). Chronic renal disease. British Medical Journal, 325, 85 - 89.

Pereira, B. (2000). Optimization of pre-ESRD care: The key to improved dialysis outcomes. Kidney International, 57, 351 - 365.

Polaschek, N. (2003). Living on dialysis: Concerns of clients in a renal setting. Journal of Advanced Nursing, 41, 44 -52.

Redman, B., Hill, M. \& Fry, S. (1997). Ethical conflicts reported by certified nephrology nurses practicing in dialysis settings. American Nephrology Nurses Association Journal, 24 (1), $23-33$.

Renal Physicians Association. (2002). Clinical practice guideline: Appropriate patient preparation for renal replacement therapy. Executive summary. Duke Evidence-based Practice Center.

Renal Physicians Association and American Society of Nephrology. (2000). Clinical practice guideline on shared decision-making in the appropriate initiation of and withdrawal from dialysis. Washington DC, Author.

Ritz, E. (2001). Advances in nephrology: successes and lessons learnt from diabetes mellitus. Nephrology Dialysis Transplantation, 16 (7), 46 - 50.

Robinson, K. (2001). Does pre-esrd education make a difference? The patients' perspective. Dialysis and Transplantation, 30 (9), 564 - 567.

Roderick, P., Jones, C., Tomson, C. \& Mason, J. (2002). Late referral for dialysis: Improving the management of chronic renal disease, Journal of Medicine, 95, $363-370$.

Sesso, R. \& Belasco, A. (1996). Late diagnosis of chronic renal failure and mortality on maintenance dialysis. Nephrology Dialysis Transplantation, 11, 2417 - 2420.

Shapiro, F.L. (1976). Innovations in health care delivery for patients with end stage renal disease (ESRD). Journal of Dialysis, 1 (1), 25 - 55.

Silverberg, D. (2003). Outcomes of anaemia management in renal insufficiency and cardiac disease. Nephrology, Dialysis and Transplantation, 18 (Supplement 2), ii7 - ii12.

Simpson, I., Bailey, R., Robson, R., Price, M., Collins, J. \& Lynn, K. (1997). Management guidelines for progressive chronic renal failure. New Zealand Medical Journal, 14 November, 421- 423.

St Peter, W.L., Schoolwerth, A.C., McGowan, T. \& McClellan, W.M. (2003). Chronic kidney disease: Issues and establishing programs and clinics for improved patient outcomes. American Journal of Kidney Disease, 41 (5), 903 - 924.

Stephenson, K. (1993). Results of a predialysis education program. Dialysis and Transplantation, $566-570$.

Stigant, C., Stevens, L. \& Levin, A. (2003). Nephrology: 4. Strategies for the care of adults with chronic kidney disease. Canadian Medical Association Journal, 168 (12), 1553 - 1564.

Stoves, J., Bartlett, C.N. \& Newstead, C.G. (2001). Specialist follow up of patients before end stage renal failure and its relationship to survival on dialysis. PostGraduate Medical Journal, 77, (911), 586 - 589.

Szromba, C. (1998). Education for predialysis patients: A continuing challenge. American Nephrology Nurses Association Journal, 25 (1), 80 - 83.

Szromba, C., Thies, M.A. \& Ossman, S. (2002). Advancing chronic kidney disease care: New imperatives for recognition and intervention. Nephrology Nursing Journal, 29 (6), 547 $-662$.

Thomas, M. \& Mathew, T.H. (2000). Slowing the progression of adult renal disease. New Ethicals Journal, 25 - 29.

Vogel, S. (2002). Cardiac disease, infectious disease, and chronic renal failure. Nephrology Nursing Journal, 29 (2), 199 - 201. 
Walker, R. (1997). Recent advances: General management of end stage renal disease. British Medical Journal, 315, 1429 -1432.

Walker, R. \& Manning, P. (1999). Diabetic nephropathy assessment and management. New Ethicals Journal, 49 -55.

White, C., Pilkey, R., Lam, M. \& Holland, D. (2002). Pre-dialysis clinic attendance improves quality of life among hemodialysis patients. BioMed Central Nephrology, 3 (3), 100 108. 